\title{
Analysis of indoor air pollutants checklist using environmetric technique for health risk assessment of sick building complaint in nonindustrial workplace
}

\author{
This article was published in the following Dove Press journal: \\ Drug, Healthcare and Patient Safety \\ 20 September 2012 \\ Number of times this article has been viewed
}

\begin{abstract}
Al Syazwan'
B Mohd Rafee'

Hafizan Juahir ${ }^{2}$

AZF Azman

AM Nizar ${ }^{3}$

Z Izwyn ${ }^{4}$

K Syahidatussyakirah

AA Muhaimin ${ }^{5}$

MA Syafiq Yunos 6

AR Anita

J Muhamad Hanafiah'

MS Shaharuddin ${ }^{7}$

A Mohd Ibthisham

I Mohd Hasmadi ${ }^{9}$

MN Mohamad Azhar'

HS Azizan'

I Zulfadhli ${ }^{10}$

J Othman"

M Rozalini' ${ }^{12}$

FT Kamarul ${ }^{13}$

'Department of Community Health, Faculty of Medicine and Health Sciences, Universiti Putra Malaysia, Selangor, ${ }^{2}$ Department of Environmental Science/ Environmental Forensics Research Center (ENFORCE), Universiti Putra Malaysia, Selangor,

${ }^{3}$ Pharmacology Unit, Department of Human

Anatomy, Faculty of Medicine and Health Sciences,

Universiti Putra Malaysia, 43400 Serdang, Selangor,

${ }^{4}$ Department of Therapy and Rehabilitation, Faculty

of Health Science and Biomedical Engineering,

Universiti Teknologi Malaysia, Johor, ${ }^{5}$ Department of

Environmental Management, Faculty of Environmental

Studies, Universiti Putra Malaysia, Selangor, ' ${ }^{6}$ Plant

Assessment Technology (PAT), Industrial Technology

Division, Malaysian Nuclear Agency, Bangi, ${ }^{7}$ Department

of Environmental and Occupational Health Science,

Faculty of Medicine and Health Sciences, Universiti

Putra Malaysia, Selangor, ${ }^{8}$ Department of Mechanical

Engineering, Faculty of Mechanical Engineering,

Universiti Teknologi Malaysia, Johor, ${ }^{9}$ Department

of Forest Production, Faculty of Forestry, Universiti

Putra Malaysia, Selangor, ${ }^{10} \mathrm{Faculty}$ of Built Environment

and Architect, Universiti Teknologi Malaysia, Johor,

"Department of Counselor Education and Psychology

Counseling, Faculty of Educational Studies, Universiti

Putra Malaysia, Selangor, ${ }^{12}$ Occupational Safety, Health

and Environment Unit, Multimedia University, Jalan

Multimedia 63100 Cyberjaya, Selangor, ${ }^{13}$ ERALAB

SDN. BHD. (Environmental Research and Analytical

Laboratory Sdn. Bhd.), Selangor, MALAYSIA
\end{abstract}

Correspondence: Aizat Ismail Syazwan

Environmental and Occupational Medicine

Unit, Department of Community Health,

Faculty of Medicine and Health Sciences,

Universiti Putra Malaysia,

43400, Serdang, Selangor, MALAYSIA

Tel $+6013-2823757$

Fax +603-8945 0151

Email syazwan@putra.upm.edu.my OR syazwan.ismail.upm@gmail.com

Purpose: To analyze and characterize a multidisciplinary, integrated indoor air quality checklist for evaluating the health risk of building occupants in a nonindustrial workplace setting.

Design: A cross-sectional study based on a participatory occupational health program conducted by the National Institute of Occupational Safety and Health (Malaysia) and Universiti Putra Malaysia.

Method: A modified version of the indoor environmental checklist published by the Department of Occupational Health and Safety, based on the literature and discussion with occupational health and safety professionals, was used in the evaluation process. Summated scores were given according to the cluster analysis and principal component analysis in the characterization of risk. Environmetric techniques was used to classify the risk of variables in the checklist. Identification of the possible source of item pollutants was also evaluated from a semiquantitative approach.

Result: Hierarchical agglomerative cluster analysis resulted in the grouping of factorial components into three clusters (high complaint, moderate-high complaint, moderate complaint), which were further analyzed by discriminant analysis. From this, 15 major variables that influence indoor air quality were determined. Principal component analysis of each cluster revealed that the main factors influencing the high complaint group were fungal-related problems, chemical indoor dispersion, detergent, renovation, thermal comfort, and location of fresh air intake. The moderate-high complaint group showed significant high loading on ventilation, air filters, and smoking-related activities. The moderate complaint group showed high loading on dampness, odor, and thermal comfort.

Conclusion: This semiquantitative assessment, which graded risk from low to high based on the intensity of the problem, shows promising and reliable results. It should be used as an important tool in the preliminary assessment of indoor air quality and as a categorizing method for further IAQ investigations and complaints procedures.

Keywords: office, indoor environment quality, indoor air quality assessor, Industry Code of Practice on Indoor Air Quality, indoor guideline, sick building syndrome, odor, IAQ assessment

\section{Introduction}

In tropical regions such as Singapore, Thailand, and Malaysia, indoor air quality (IAQ) issues are very challenging in building design, engineering, and facility management. The high humidity and temperatures experienced in countries near the equator increase the risk of thermal discomfort, moisture problems, and other indoor air issues. ${ }^{1}$ In Malaysia, a published updated legislation was implemented in 2010 when the Department of Occupational Safety and Health (DOSH) under the Ministry 
of Human Resources launched the Industry Code of Practice on IAQ (ICOP-IAQ), with the primary aim of ensuring that employers work voluntarily in assessing risks of IAQ in the workplace. ${ }^{2}$ Generally, good IAQ is required for a healthy indoor work environment. Poor IAQ can lead to variety of short-term and long-term health problems. Health problems commonly associated with poor IAQ include respiratory problems, eye irritation, sinusitis, allergic reactions, pneumonia, and bronchitis. IAQ problems occur in buildings that are commonly served by a mechanical ventilating and air conditioning (MVAC) system (called a heating, ventilation, and air conditioning system in four-season countries; the heating element is not useful in tropical regions), eg, air-cooled split unit. ${ }^{2}$

There are many sources of indoor air pollutants; one of the most common sources is environmental tobacco smoke emitted from the burning of tobacco products. Environmental tobacco smoke is one of the major issues discussed among researchers in Malaysia that directly affect the indoor air in the office. ${ }^{3}$ Beside environmental tobacco smoke, other various chemical substances may directly influence the quality of air served by an MVAC system, eg, volatile organic compounds emitted from the use and application of solvents, ozone emitted from photocopiers and laser printers, and formaldehyde emitted from furnishings. ${ }^{1,4,5}$

In recent years, many occupational health and safety (OSH) professionals have been aware of, and concerned about, the IAQ issues in their nonindustrial workplace. However, a challenge arose when OSH professionals had difficulty in "predetermining" the air quality served by MVAC. The ICOP-IAQ standard was drawn up to ensure that employees and occupants are protected from poor IAQ that could adversely affect their health and wellbeing and thereby reduce their productivity. As stipulated under section 15 of the Malaysian OSH Act 1994, the code (ICOP-IAQ) functions as the general duties of employers and self-employed persons to their employees; however, section 17 stipulates that it is also the general duties of employers and self-employed persons to persons other than their employees. Based on this justification, some difficulties and challenges arose for OSH professionals in regards to determining whether or not their building is healthy.

Therefore, a way to easier quantify risk elements indoors is needed. Besides the preventive medicine approach, IAQ issues as stated in ICOP-IAQ also emphasize the duties of an occupier of a place of work to persons other than his employees, as stipulated in section 18 of the OSH Act 1994. An occupier is a person who has management or control of the place of work. This stipulation covers persons who are not employees but go to an occupier's premises to carry out work. Compliance to this ICOP can be used as evidence of good practice in a court. ${ }^{2,3}$

As governments seriously implement this code and standard, many engineers and OSH professionals encounter a big challenge in determining the IAQ risk. Some researchers suggest that engineers and building owners should take positive/preventive action by installing ultraviolet germicidal irradiation devices to reduce the risk of microbial contaminants, ${ }^{6}$ and implement a good plan of preventive maintenance, surface treatment, and air purifiers. ${ }^{7}$ Many engineers suggest OSH researchers should come up with a scoring method that quantitatively correlates with the level of indoor pollutants. ${ }^{8}$

Therefore, there is a need to quantify the risk element for indoor air pollutants by using a published checklist that is validated according to the existing occupational exposure samples. To understand the pollutants in the indoor environment, researchers suggest that common pollutants exist indoors for several reasons, eg, occupant activities, inadequate material or material with technical defects used in the construction of the building, work performed in the indoor environment (eg, carpet cleaning), excessive or improper use of normal products (eg, pesticide, disinfectants, products used for cleaning and polishing), combustion gases (eg, from smoking), and cross-contamination coming from other poorly ventilated zones. ${ }^{6-8}$

Environmetrics is an important branch in environmental sciences, analytical chemistry, and modern statistical modeling that uses multivariate techniques to analyze data - described by some researchers as chemometrics. ${ }^{9}$ Environmetrics is a cost effective technique with good strategies and scientifically sound statistical interpretation of complex environmental monitoring data. ${ }^{10}$ Environmetric analysis can be used to develop more meaningful information from public, environmental, and occupational health monitoring data. Environmetric methods can provide sufficient informative classification of samples (observations) or identification of pollution sources and sampling locations. ${ }^{11-15}$

Environmetrics has also been used to evaluate and characterize environmental quality data (water, air, land) and to detect spatial variations caused by environmental or natural factors. ${ }^{16,17}$ Recently, environmetric techniques have become a significant device in environmental and occupational health to evaluate and reveal complex relationships of data in a wide discipline of public, environmental, and occupational 
hygiene applications. ${ }^{18,19}$ Hierarchical agglomerative cluster analysis (HACA) and the principal component analysis (PCA) with factor analysis (FA) are the common environmetric methods used in the evaluation of environmental monitoring data. ${ }^{20}$ Besides PCA and FA, discriminant analysis (DA) is commonly being used as a supporting analysis to make a confirmatory analysis for HACA and PCA, and sometimes for statistical pattern recognition. ${ }^{21}$ Dissimilar pattern recognition methods help to reduce the complication of data and to ensure that the analysis will better interpret the environmental data. ${ }^{22,23}$

The objective of this study was to evaluate and characterize the risk element of IAQ using the IAQ checklist and environmetric methods. The environmetric evaluation includes clustering the pollutants according to its group and PCA for assessing the correlation between items in the checklist.

The data in this study are taken from the IAQ monitoring program (semiqualitative assessment) of 2010-2011. Environmetric methods were used to identify the influence of itemized pollutants on the IAQ checklist. From the information obtained in this study, a critique on the IAQ checklist methodology will be further used as a reliable instrument to predict the IAQ index in an indoor environment. This specific article will focus on clustering, managing, and identifying the element of risk of itemized pollutants that influence indoor environmental quality issues, whether good, moderate, or bad. By using three components of multivariate analysis - HACA, DA, and PCA, the major influence of the pollutants will be summarized and further analyzed with the quantitative data. Comparison of the quantitative data (indoor air monitoring data) and the semiquantitative data will be presented elsewhere.

\section{Material and methods Description of the IAQ checklist}

The IAQ checklist was firstly developed by Syazwan et al using a multidimensional action checklist to evaluate and suggest important criteria that may influence a building's IAQ. ${ }^{8}$ The new multidimensional IAQ checklist that was formulated consists of seven core areas, nine technical areas, and 71 essential items. ${ }^{8}$ In addition to the technical areas covered from the previous ICOP checklist, several new areas were suggested to improve the IAQ checklist. The constructed IAQ checklist, based on the literature and discussion with OSH professionals, identified the main items characterizing risk to IAQ: pollution, ventilation, human exposure to pollutants, and other factors.

\section{Description of study samples}

The checklist was distributed and given to OSH practitioners, architects, engineers, general workers, and occupational health researchers at the National Institute of $\mathrm{OSH}$ (Malaysia). In Malaysia, most OSH practitioners, general workers, architects, and engineers need to update their knowledge on safety and health through continuing education at the National Institute of OSH. About 130 checklists were distributed at the center and 102 completed checklists were successfully obtained.

Complete IAQ assessment was proposed to each of the 102 respondents (ie, 102 buildings), and the quantitative and health-related complaint data were further collected. Additional samples of the IAQ assessment program were also collected from a different type of predetermined industry under the OSH Act 1994 to further develop the IAQ risk matrix. Data on the quantitative and risk matrix will be presented elsewhere.

\section{The checklist evaluation}

The evaluation of the checklist aimed to determine how occupants complain about the general IAQ condition in their workplace (nonindustrial setting such as office) and the quantitative level of pollutants conducted by the IAQ assessor. The general idea of this exercise was to score each checklist (published by DOSH; scoring method suggested by previous researcher) and compare it with the quantitative level of the pollutants. This mechanism will help small and medium enterprises and other general office areas to predetermine the condition of IAQ as good, moderate, or bad, and thus initiate a detailed quantitative testing of the airborne pollutants indoors.

This checklist evaluation will cluster the total perceived complaints, discriminate the level associated with the clusters, and determine the factors influencing the complaints. This method will allow a general overview of the suspected source of pollutants to be further compared with the quantitative data gathered using scientific instruments, and the risk matrix of IAQ to be produced.

\section{Statistical analysis}

Environmetric methods - namely, HACA, PCA, FA, and DA - were used to study the variations and major factors that influence the level of IAQ variables (from the checklist) and to determine the possible origin of pollution generated indoors or elsewhere. HACA, DA, PCA, and FA were conducted using XLSTAT-Pro 2010 for Microsoft Excel ${ }^{\circledR}$ (Addinsoft, New York, NY) and IBM ${ }^{\circledR}$ 
SPSS version 15.0 for Windows (IBM SPSS, Armonk, NY). All variables were found to be significantly different/ correlated if $P<0.05$.

\section{Cluster analysis}

HACA was used to explore the combination of the sites (spatial) to represent the condition of the occupants' facility. It has been previously suggested that HACA is commonly used for classifying and categorizing cases or variables (observations/samples) into different clusters by comparing their homogeneity level within class and the heterogeneity level between classes, with inclusion and exclusion criterion selected by the researcher. ${ }^{24,25}$ Ward's method is commonly used with the application of Euclidean distances as a measuring point of similarity within HACA. ${ }^{22,26,27}$ The results from HACA are usually illustrated with a dendogram, which presents the arrangement of clusters. ${ }^{28}$ The Euclidean distance (linkage distance) is typically reported as $\mathrm{D}_{\text {link }} / \mathrm{D}_{\text {max }}$, ie, linkage distance divided by maximal distance. The amount is frequently multiplied by 100 as a strategy to regulate the linkage represented by the Y-axis. ${ }^{15,17}$

\section{DA and index summated score}

DA is a multivariate statistic for determining the variables that discriminate among two or more naturally happening clusters/groups. It develops a discriminant function for each category as described by Johnson and Wichern. ${ }^{29}$ Discriminant functions are calculated using the following equation:

$$
f\left(G_{i}\right)=k_{i}+\sum_{j=1}^{n} w_{i j} P_{i j}
$$

In this equation, $i$ is the number of categories/classes/ groups $(G), k_{i}$ is the constant factor in each group, $n$ is the parameters used to classify the data set into a predetermined group, and $w_{i j}$ is the weight coefficient, known as discriminant function analysis to a given parameter $\left(P_{i j}\right)$. In this study, DA was applied to establish whether the groups fluctuate with regard to the mean of a variable, and to use that variability to forecast group membership.

The multivariate DA was then analyzed using raw data in standard, forward stepwise, and backward stepwise modes. These methods were used to obtain the discriminant function value and then evaluate their variations in the IAQ checklist items. The location/type/name of the building (spatial) represented the dependent variables, while all the measured parameters (IAQ checklist questions) represented the independent variables. In the forward stepwise mode, variables were added step by step, starting with the most important variable until no significant changes were obtained $(P>0.05)$. In the backward stepwise mode, variables were removed step by step, starting with the less significant variable until no significant changes were obtained.

Three groups, classified by cluster analysis, were selected for spatial analysis (complaints perceived by $\mathrm{OSH}$ personnel - high complaint [HC], moderate-high complaint [MHC], and moderate complaint [MC]). Justification for the classification of the complaint was based on the summated score obtained for each sample divided by the highest risk available, eg, summated score of 25 divided by 25 [total score for worst scenario - five complaints, score of five for the worst situation], to form an index. ${ }^{30,31}$ Based on this method, the index can be calculated which shows the relative difference between each cluster. Based on the evaluation of the index, the HC group scored between $0.41-0.56$ with mean \pm standard deviation of $0.46 \pm 0.057$ (the high mean indicates that the level of complaint will be the highest, ie, more than 50\%), the MHC group scored between 0.19-0.47 with mean \pm standard deviation of $0.34 \pm 0.069$ (considerable high mean, but below the highest), and the MC group scored between $0.28-0.43$ with mean \pm standard deviation of $0.34 \pm 0.026$ (based on the mean projection near to $\mathrm{MHC}$; however, other classification considered due to variation of the standard deviation). The classification of $\mathrm{HC}, \mathrm{MHC}$, and $\mathrm{MC}$ was solely based on the perceived complaint index (suggested by the previous checklist) ${ }^{8}$ developed during the analysis of the whole data set.

\section{PCA/FA}

PCA is the most useful blueprint recognition technique in the evaluation of this specific IAQ checklist that is usually tied with HACA. It gives important information on the most significant parameters (most prominent values, thus $P<0.05)$ due to variations that occur in the data set by excluding the less important parameters. ${ }^{15,17}$ The PCA can be expressed as:

$$
z_{i j}=a_{i 1} x_{1 j}+a_{i 2} x_{2 j}+\cdots+a_{i m} x_{m j}
$$

In this equation, $z$ is the factor score, $a$ is the factor loading, $x$ is the calculated value of the variable, $i$ is the factor number, $j$ is the section number, and $m$ is the total number of variables. FA is usually applied to interpret complex data matrix (large numbers) and offers a promising detection of similarities among variables or samples. ${ }^{32}$ The principal components generated by PCA are sometimes not really 
interpreted; rotation of the principal components is needed, eg, by varimax rotation. Eigenvalues greater than one are considered to be significant, ${ }^{33}$ which is one of the key elements in the varimax rotation for forming a new group of variables named varimax factors (VFs). VF coefficients greater than 0.75 are considered as "strong," $0.75-0.50$ as "moderate," and 0.50-0.30 as "weak" significant factor loadings. ${ }^{18,34}$ Identification of the factors that influence the IAQ of the indoor environment was made on the basis of different activities in the building and previous literature. The basic concept of FA is expressed as:

$$
z_{i j}=a_{j 1} f_{1 i}+a_{f 2} f_{2 i}+\cdots+a_{j m} f_{m i}+e_{j i}
$$

In this equation, $z$ is the calculated value of a variable, $a$ is the component loading, $f$ is the factor score, $e$ is the excess term accounting for errors or other sources of deviation, $i$ is the sample number, $j$ is the variable number, and $m$ is the total number of factors.

In this study, PCA/FA was used to analyze the data sets (23 variables) independently for the three different spatial IAQ conditions (complaints) - HC, MHC, and $\mathrm{MC}$ - as classified by cluster analysis. The input data matrices (variables $\times$ cases) for PCA/FA were $68 \times 9$ for $\mathrm{HC}, 68 \times 120$ for $\mathrm{MHC}$, and $68 \times 44$ for $\mathrm{MC}$.

\section{Results}

\section{Semiquantitative score classification based on the IAQ checklist}

This section discusses the present values of IAQ parameters, using the IAQ checklist,${ }^{8}$ in order to classify the factorial IAQ parameters/components based on HACA. HACA was performed on the IAQ semiquantitative data set to evaluate variation among the respondent responses. A summary of the buildings being assessed is shown in Table 1.This analysis resulted in the grouping of factorial components into three clusters/groups (Figure 1). The cluster analysis shows the grouping of three important categories, merged into one significant group (Figure 1). This group represents cluster 1/ $\mathrm{HC}$ (due to the highest index number scored by respondents), cluster 2/MHC (due to the pattern of the index number scored by respondents that was nearly the highest scored; this was to ensure the correct classification can be made upon further multivariate testing), and cluster $3 / \mathrm{MC}$ (due to the lower index summated scores recorded among respondents; this cluster was categorized as medium class due to its potential numerical model to achieve high values). Cluster 1 represents the $\mathrm{HC}$ from early observations, cluster 2 represents the $\mathrm{MHC}$
Table I General building characteristics of the study samples

\begin{tabular}{|c|c|c|c|}
\hline Variables & Item & Frequency (\%) & Mean (SD) \\
\hline Age & & & $7.36(3.81)$ \\
\hline \multirow[t]{10}{*}{ Sector } & Construction & $3(2.9)$ & \\
\hline & Factory & $10(9.8)$ & \\
\hline & Services & $10(9.8)$ & \\
\hline & Education & $18(17.6)$ & \\
\hline & Government & $21(20.6)$ & \\
\hline & Local authority & $9(8.8)$ & \\
\hline & Healthcare facilities & $13(12.7)$ & \\
\hline & Private sector & $3(2.9)$ & \\
\hline & Agriculture & $9(8.8)$ & \\
\hline & Oil and gas & $6(5.9)$ & \\
\hline \multirow[t]{3}{*}{ Ventilation } & Split unit system & $23(22.5)$ & \\
\hline & Centralized unit system & $68(66.7)$ & \\
\hline & $\begin{array}{l}\text { Mix (centralized and } \\
\text { split unit system) }\end{array}$ & II (I0.8) & \\
\hline History of & Minor/no issues & $21(20.6)$ & \\
\hline \multirow[t]{2}{*}{ complaint } & Moderate/medium & $62(60.8)$ & \\
\hline & Major/many episodes & $19(18.6)$ & \\
\hline \multirow[t]{2}{*}{ Carpeting } & No & $60(58.8)$ & \\
\hline & Yes & $42(4 \mid .2)$ & \\
\hline Other IEQ- & No issues & $29(28.4)$ & \\
\hline \multirow[t]{2}{*}{ related issues } & Minor issues & $58(56.9)$ & \\
\hline & Moderate issues & $15(14.7)$ & \\
\hline
\end{tabular}

Abbreviations: IEQ, indoor environmental quality; SD, standard deviation.

from observations in the middle, and cluster 3 represents the MC from observation end.

This result shows that a single assessment of IAQ by semiquantitative approach, only one complaint risk index in each cluster, is needed to correspond to a logically accurate IAQ assessment for the whole assessment exercise. Cluster analysis reduces the need for extended hygiene sampling and quantitative assessment. Monitoring from three complaint indexes is sufficient for a clear understanding of pollutants.

Figure 1 shows the cluster of the three main complaints given by HACA and the possible pollution sources within the study classification (according to building complaints). The clustering method produced three groups/clusters in a very simplified way, as the respondents in these groups have similar distinctiveness when using semiquantitative evaluation. All items in Figure 2 indicate a summary of the findings in the evaluation of spatial DA by respondents scored.

To study the variation among OSH representatives, DA was analyzed on the raw data of the IAQ checklist and divided into three main groups defined by cluster analysis. Groups of $\mathrm{HC}, \mathrm{MHC}$, and $\mathrm{MC}$ were defined as dependent variables, while IAQ checklist parameters were treated as independent variables. DA was analyzed using standard, forward stepwise, and backward stepwise methods. The accuracy of classification using standard, forward stepwise, and backward stepwise mode 


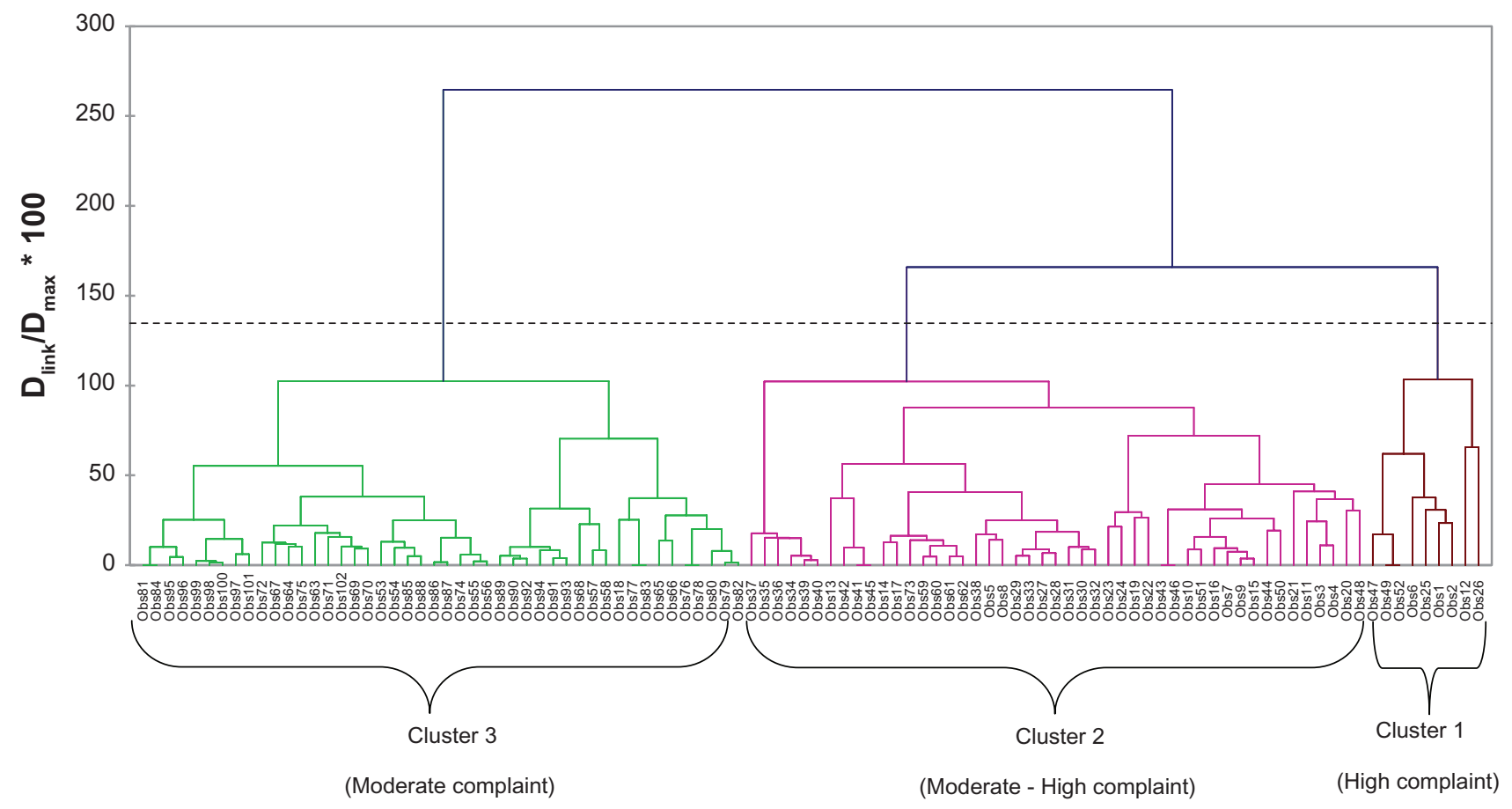

Figure I Dendogram of the observation result of cluster analysis using Ward's method. Abbreviations: $D_{\text {link }}$, linkage distance; $D_{\text {max }}$, maximal distance.

discriminant function analysis was $96.08 \%$ (15 discriminant variables), $98.04 \%$ (20 discriminant variables), and $96.08 \%$ (28 discriminant variables), respectively (Table 2).

Using standard DA, fungal (Figure 2A), air freshener (Figure 2B), hazardous substance (Figure 2C), radiant heat (Figure 2D), window heat index (Figure 2E), dead air (Figure 2F), occupant change (Figure 2G), furnishings odor (Figure 2H), gas (Figure 2I), supply (Figure 2J), noise (Figure 2K), general (Figure 2L), conduct (Figure 2M), IAQ assessment conducted (Figure $2 \mathrm{~N}$ ), and interest in IAQ (Figure 2O) were found to be the significant variables (variables were found to be significant at $P<0.05$ ).

Forward and backward stepwise modes included another 5-13 parameters with high variation. Fifteen selected IAQ checklist parameters that gave high variations $(P<0.05)$ by standard stepwise DA were then used for further discussion and testing for PCA and FA.

PCA was used on the data set to observe the pattern between the IAQ checklist and the factors influencing each of the identified complaint classifications (HC, MHC, and $\mathrm{MC}$ ). Seven principal components were obtained for $\mathrm{HC}$ and seventeen principal components were obtained for the other two complaint classifications (MHC and MC), with eigenvalues larger than one summing $95.44 \%, 86.73 \%$, and $88.74 \%$ of the total variance in the data set, respectively. Corresponding VFs, variable loadings, and variance explained are presented in Table 3.

\section{Discussion}

\section{Variation of IAQ checklist numerical index calculation}

General variation of the study demonstrated by environmetric techniques is described elsewhere. ${ }^{35,36}$ The spatial element of the data represents the condition of the building and is a major indicator for the IAQ analysis condition, ie, could

Table 2 Classification matrix for discriminant analysis of spatial variations in indoor air quality checklist evaluation

\begin{tabular}{lllll}
\hline Sampling & \% correct & \multicolumn{3}{l}{ Group assigned by DA } \\
\cline { 3 - 5 } complaint & & HC & MHC & MC \\
\hline Standard DA mode & (I5 variables) & & & \\
HC & 87.50 & 7 & 0 & 1 \\
MHC & 93.75 & 0 & 45 & 3 \\
MC & 100 & 0 & 0 & 46 \\
Total & 96.08 & 7 & 45 & 50 \\
Forward stepwise & mode (20 variables) & & & \\
HC & 100 & 9 & 0 & 0 \\
MHC & 95.83 & 0 & 46 & 2 \\
MC & 100 & 0 & 0 & 45 \\
Total & 98.04 & 9 & 46 & 47 \\
Backward stepwise mode (28 variables) & & & \\
HC & 100 & 9 & 0 & 0 \\
MHC & 93.75 & 0 & 45 & 3 \\
MC & 97.78 & 0 & 1 & 44 \\
Total & 96.08 & 9 & 46 & 47 \\
\hline Abren
\end{tabular}

Abbreviations: DA, discriminant analysis; $\mathrm{HC}$, high complaint; MC, moderate complaint; MHC, moderate-high complaint. 
A

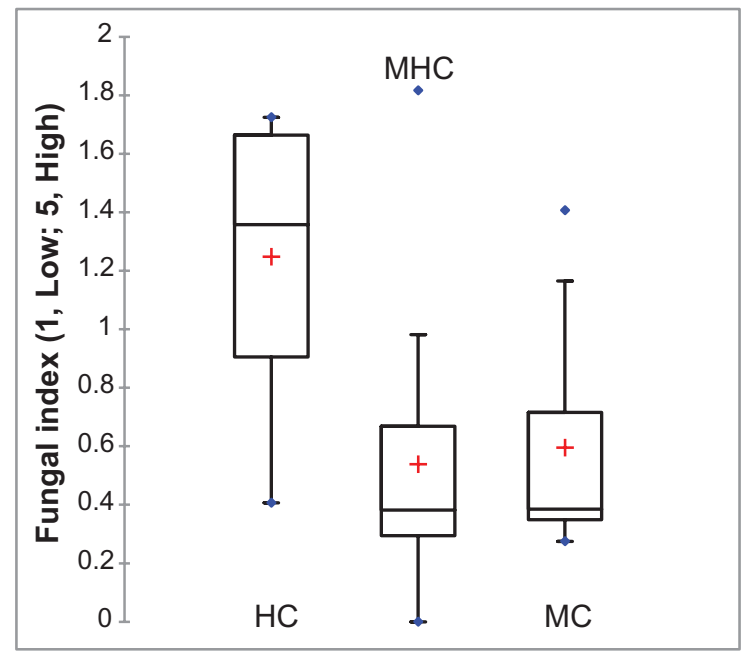

C

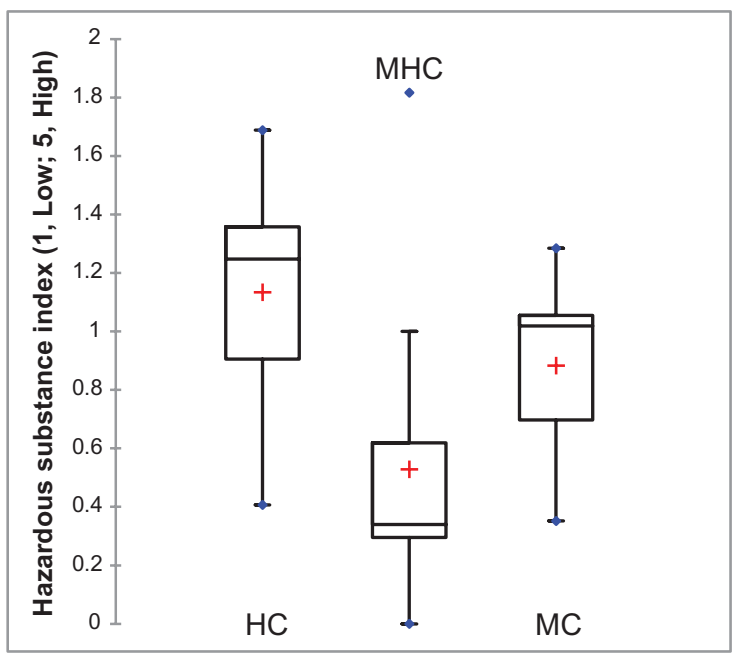

E

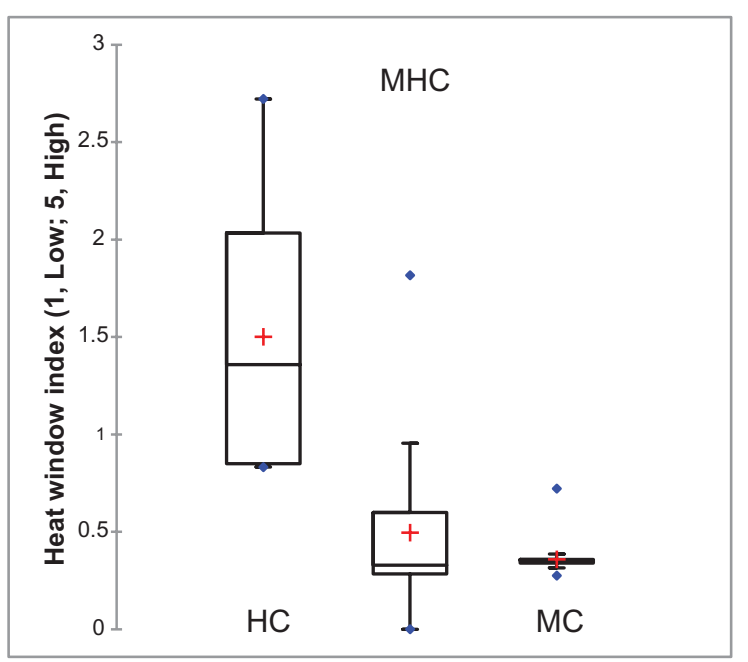

B

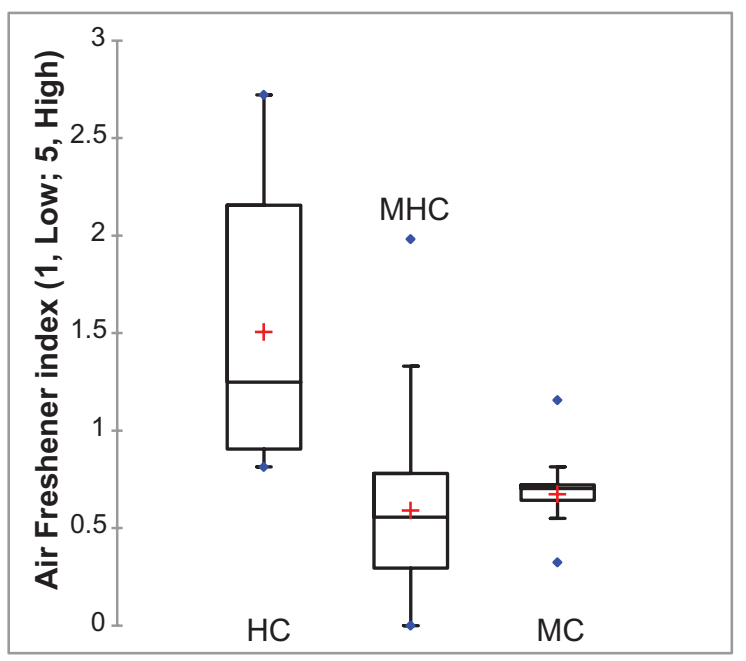

D

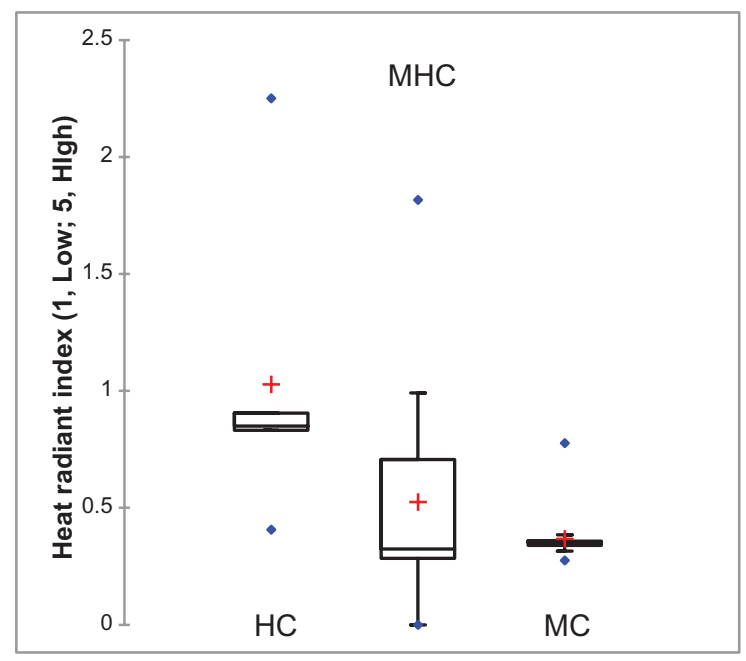

$\mathbf{F}$

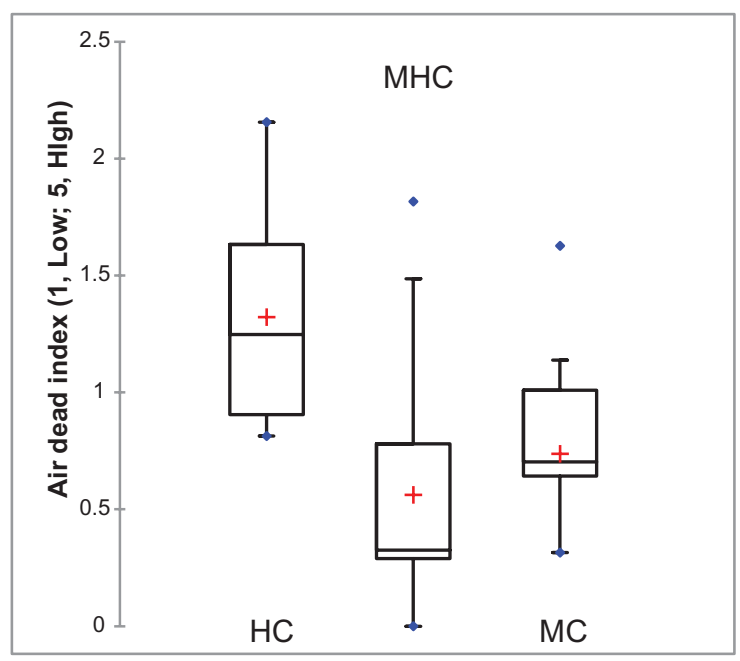

Figure 2 (Continued) 
G

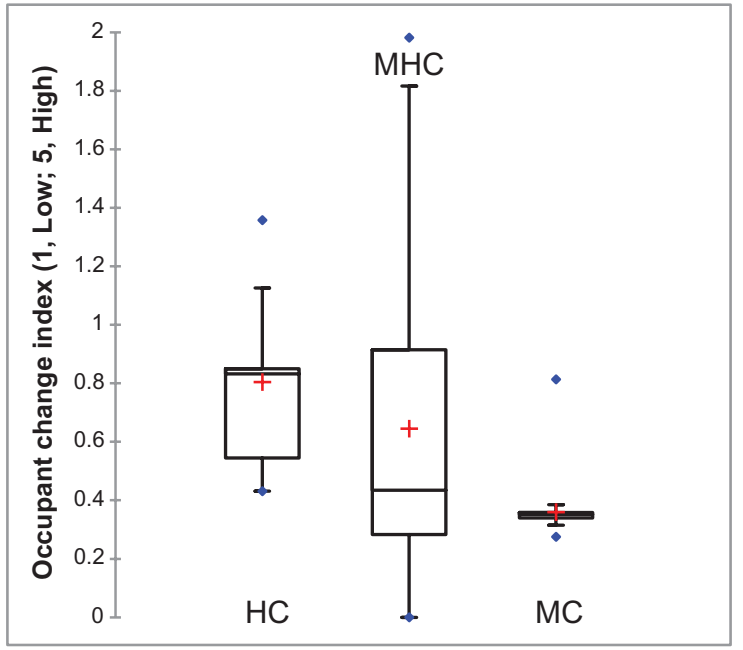

\section{I}

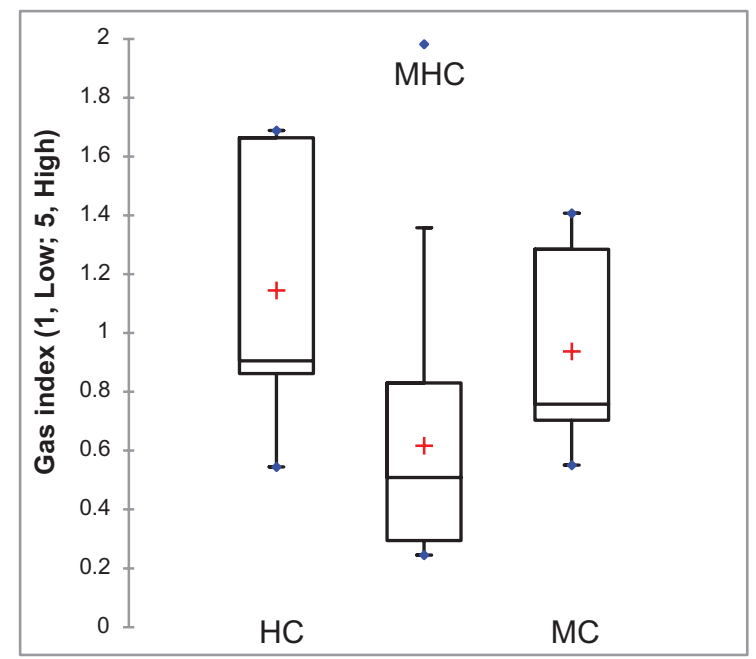

K

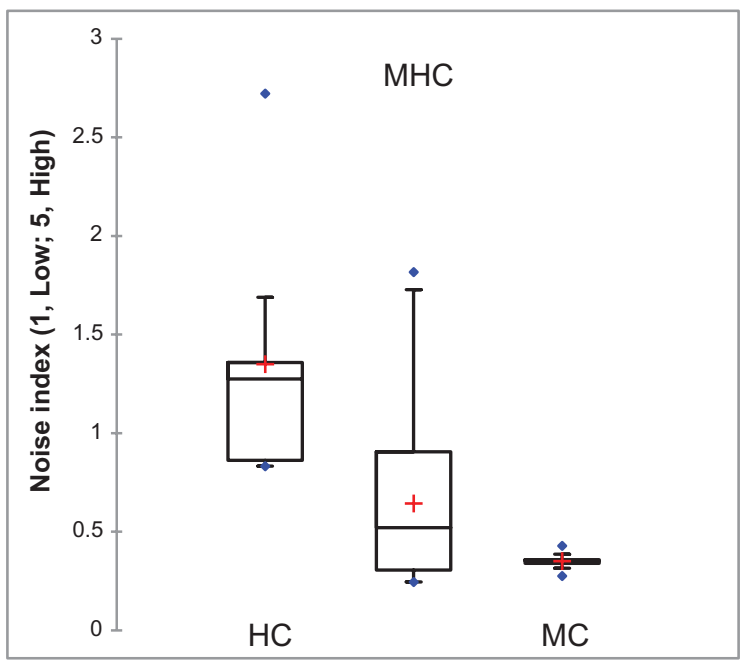

H

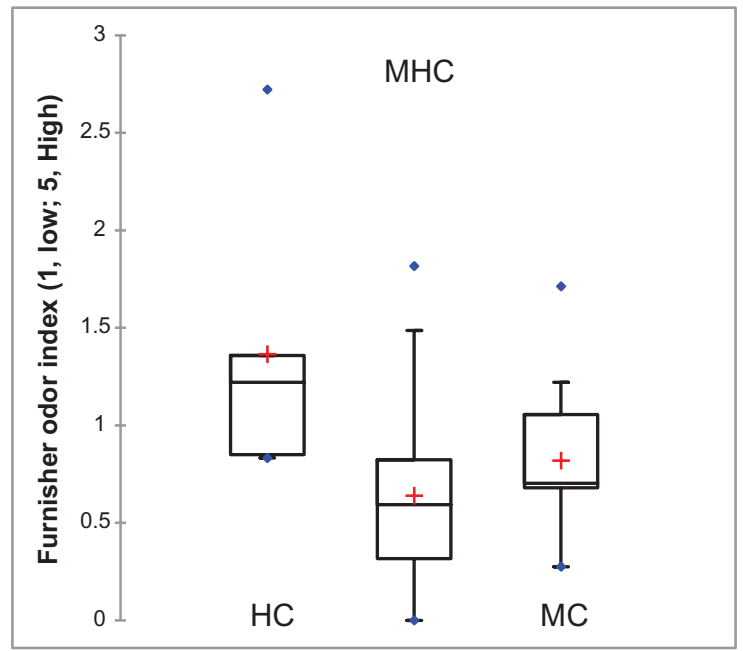

J

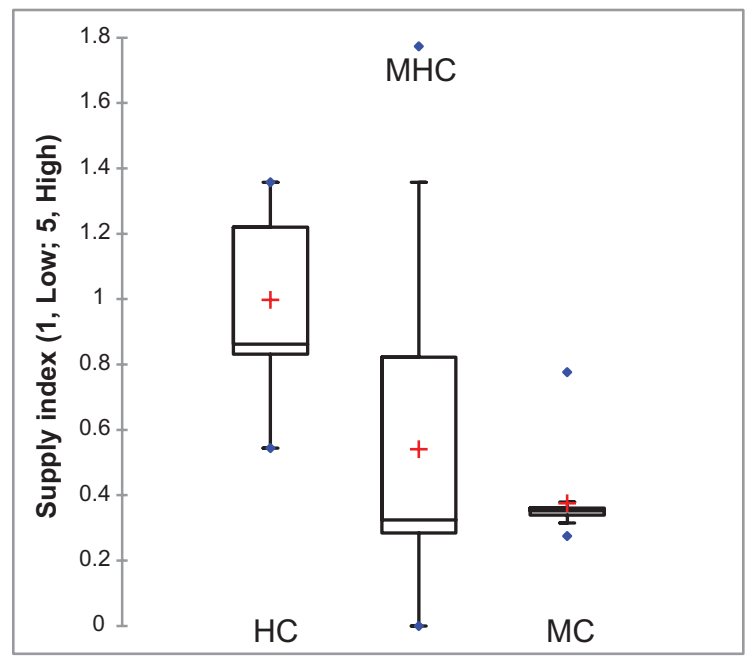

$\mathbf{L}$

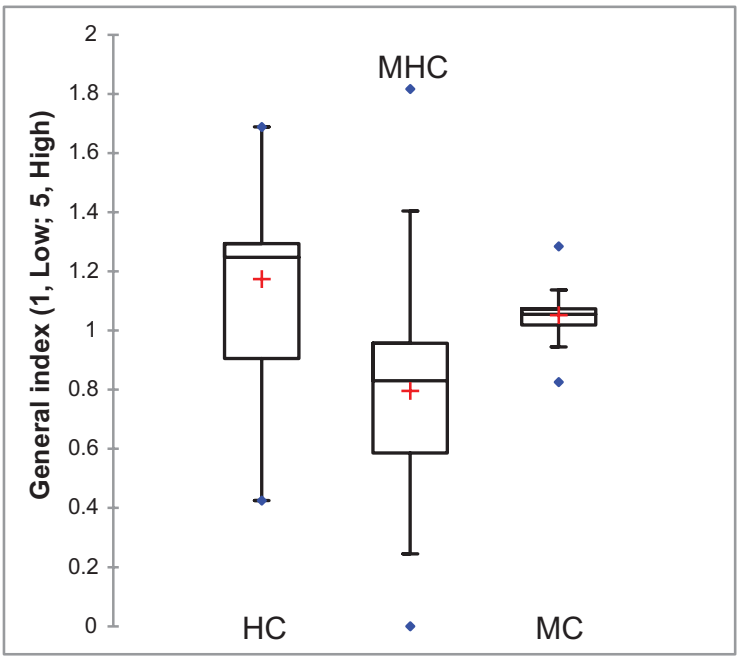

Figure 2 (Continued) 
M

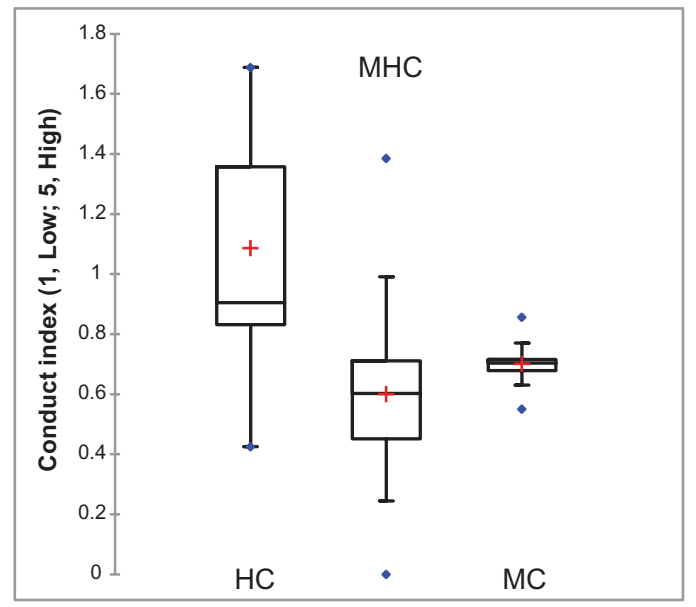

\section{$\mathbf{N}$}

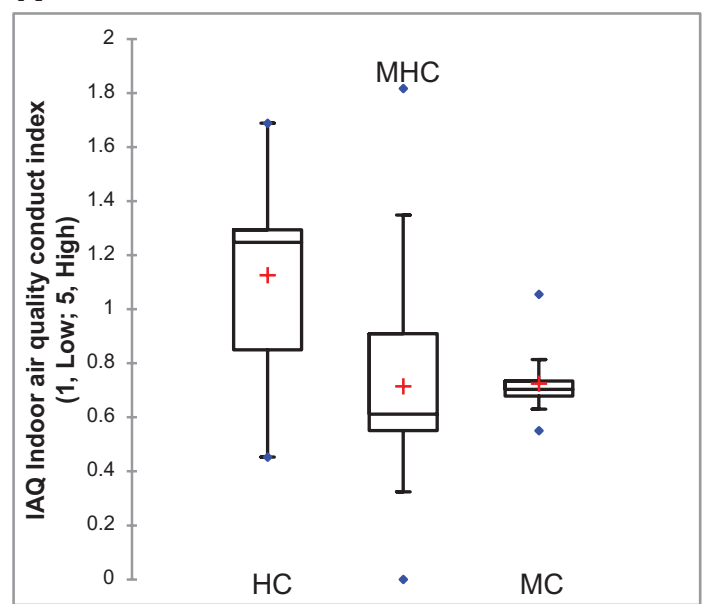

0

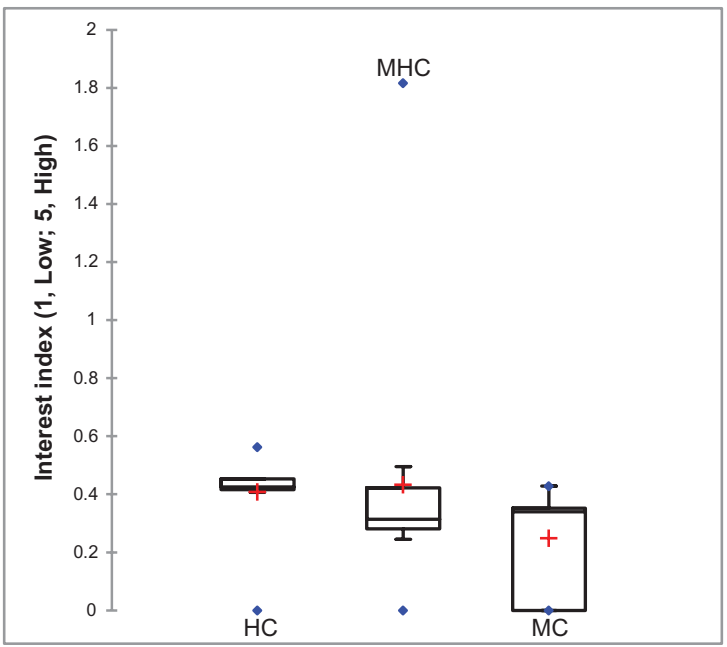

Figure 2 Box and whisker plots of some parameters separated by spatial discriminant analysis associated with the indoor air quality checklist. The parameters include: (A) fungal, (B) air freshener, (C) hazardous substance, (D) radiant heat, (E) window heat index, (F) dead air, (G) occupant change, (H) furnishings odor, (I) gas, (J) supply, (K) noise, (L) general, (M) conduct index (IAQ issues in company), (N) indoor air quality conduct, and (O) interest.

Abbreviations: $\mathrm{HC}$, high complaint; IAQ, indoor air quality; MC, moderate complaint; MHC, moderate-high complaint.

predetermine IAQ-related symptoms in buildings. To evaluate the cluster, the data was computed to produce an index score as described by Syazwan., ${ }^{3,8}$

\section{$\mathrm{HC}$ description of response from IAQ checklist}

Among the seven VFs, VF1 explaining $30.64 \%$ of the total variance, had strong positive loadings for complaints on discoloration, drain pan condition, ventilation, intended use of building, detergent, renovation, renovation during working hours, prescribed activities, alteration of air flow, kitchen/pantry condition, cleanliness, dustiness, dusty ventilation, MVAC turning off, outside air near carpark, heavy industries nearby, odor, general IAQ (poor), IAQ condition (poor), and IAQ assessment. These factors show strong linkage between IAQ issues and human response. Building deterioration, ventilation, cooling coil, and drain pan condition is a good indicator of a building having IAQ issues. It has been suggested that the problems of most buildings is due to the ventilation. ${ }^{37}$ Intended usage of the building has also been shown to be a good indicator. Insufficient evaluation by the previous owner of building usage and cleanliness leads to the high scoring of pollutants and complaints from occupants due to the health risk threat when working inside. Renovation also creates a possible link between health risk and comfort, ${ }^{3,8}$ which suggests that work permits and hazard identification prior to renovation or activities that pose a health risk should be conducted by OSH professionals. Another aspect influencing the $\mathrm{HC}$ group classification in VF1 was the intake 
Table 3A Factor loadings after Varimax rotation for HC

\begin{tabular}{|c|c|c|c|c|c|c|c|}
\hline & DI & D2 & D3 & D4 & D5 & D6 & D7 \\
\hline G_IPerception_Odor & -0.06 & 0.15 & 0.46 & 0.79 & 0.36 & -0.05 & 0.07 \\
\hline G_2Odor & -0.52 & 0.82 & 0.18 & -0.12 & 0.01 & 0.02 & 0.12 \\
\hline G_3Dirty & -0.53 & 0.47 & -0.07 & 0.45 & 0.02 & 0.40 & 0.37 \\
\hline G_4Fungal & -0.09 & -0.86 & 0.17 & 0.26 & -0.24 & 0.26 & 0.19 \\
\hline G_5Discoloration & -0.79 & -0.33 & -0.24 & 0.45 & -0.02 & 0.06 & -0.03 \\
\hline G_6Drainpan_Cooling & -0.85 & -0.37 & 0.11 & -0.19 & 0.05 & 0.27 & 0.11 \\
\hline G_7Ventilation & -0.82 & 0.05 & 0.24 & -0.01 & -0.21 & 0.03 & 0.47 \\
\hline G_8BlockageVent & -0.16 & 0.04 & 0.09 & 0.20 & 0.19 & 0.93 & 0.17 \\
\hline G_9Temperature & 0.29 & 0.68 & 0.15 & 0.07 & 0.30 & 0.33 & 0.47 \\
\hline G_100vercrowding & -0.40 & 0.63 & -0.24 & -0.09 & 0.47 & -0.35 & -0.20 \\
\hline G_IIFilters & -0.33 & 0.07 & 0.18 & 0.01 & 0.06 & 0.01 & 0.92 \\
\hline G_12 AirCleaners & -0.54 & 0.14 & 0.36 & 0.00 & -0.10 & -0.10 & 0.74 \\
\hline G_I3HazardousSub & -0.52 & -0.07 & 0.62 & 0.10 & -0.42 & 0.27 & 0.29 \\
\hline G_I4Mechanical_Room & -0.13 & 0.10 & 0.10 & 0.56 & 0.06 & 0.31 & 0.74 \\
\hline G_I5DampnessProb & -0.21 & -0.74 & -0.43 & 0.29 & -0.18 & 0.30 & 0.11 \\
\hline HE_2 WorkHours & -0.43 & -0.42 & -0.32 & 0.69 & 0.22 & 0.13 & 0.06 \\
\hline HE_3Thermostat & 0.15 & 0.94 & 0.02 & 0.16 & -0.20 & 0.15 & 0.02 \\
\hline HE_4ThermoStat_Regulate & -0.08 & 0.68 & 0.11 & 0.22 & -0.33 & -0.59 & 0.10 \\
\hline HE_5HeatRadiant & 0.02 & -0.42 & 0.37 & 0.63 & -0.11 & -0.30 & 0.44 \\
\hline HE_6HeatFrom_Window & -0.34 & 0.57 & 0.04 & -0.08 & 0.31 & -0.65 & 0.18 \\
\hline HE_7RHTemp_Check & -0.04 & 0.84 & -0.44 & 0.08 & -0.17 & -0.23 & 0.12 \\
\hline HE_8 AirDead & -0.50 & -0.34 & 0.19 & 0.08 & -0.38 & -0.24 & 0.63 \\
\hline HE_9IntendedUse & 0.88 & 0.21 & -0.22 & 0.26 & 0.07 & -0.08 & -0.23 \\
\hline HE_IO Partition & 0.38 & -0.76 & 0.46 & 0.12 & 0.19 & -0.04 & 0.12 \\
\hline HE_IIOccupnt_Change & 0.59 & -0.20 & 0.32 & -0.04 & 0.32 & -0.13 & -0.63 \\
\hline SR_ISmoking & -0.20 & -0.09 & 0.89 & -0.15 & 0.17 & 0.31 & 0.11 \\
\hline SR_2Furnish_Odor & -0.16 & 0.91 & 0.31 & 0.05 & 0.16 & 0.00 & 0.14 \\
\hline SR_3Detergent & 0.95 & 0.12 & 0.00 & 0.26 & -0.05 & 0.12 & -0.02 \\
\hline SR_4Reno & 0.80 & 0.29 & -0.20 & -0.38 & 0.28 & -0.13 & -0.06 \\
\hline SR_5Reno_WorkHour & 0.88 & -0.38 & 0.02 & -0.29 & 0.05 & 0.00 & 0.02 \\
\hline SR_6Prescribe & 0.62 & -0.44 & -0.47 & -0.25 & 0.35 & -0.11 & -0.08 \\
\hline SR_7 AlterAirFlow & 0.93 & 0.03 & 0.17 & -0.23 & -0.06 & -0.14 & -0.17 \\
\hline SR_8 Kitchen & 0.93 & 0.03 & 0.17 & 0.23 & -0.06 & -0.14 & -0.17 \\
\hline SR_9Clean & -0.66 & 0.41 & 0.44 & -0.23 & -0.14 & 0.17 & 0.33 \\
\hline SR_IODust & 0.55 & 0.54 & 0.28 & 0.04 & 0.46 & 0.34 & -0.07 \\
\hline SR_IIVacum & 0.32 & -0.09 & 0.22 & 0.07 & 0.91 & 0.02 & -0.04 \\
\hline SR_12OffGases & -0.34 & -0.64 & 0.15 & 0.18 & 0.23 & 0.15 & -0.59 \\
\hline VE_IType & 0.24 & 0.44 & -0.02 & -0.01 & 0.83 & -0.23 & 0.08 \\
\hline VE_2SuppDif & 0.30 & -0.02 & -0.29 & 0.28 & -0.44 & -0.30 & -0.67 \\
\hline VE_3Blockage & -0.06 & -0.01 & -0.28 & 0.80 & -0.13 & -0.18 & -0.47 \\
\hline VE_4Dust & -0.85 & 0.09 & 0.33 & -0.32 & -0.11 & 0.02 & 0.19 \\
\hline VE_5TurnOff_Day & 0.80 & $-0.5 \mathrm{I}$ & 0.26 & -0.02 & 0.18 & -0.02 & 0.07 \\
\hline VE_6TurnOff_OutOffice & 0.14 & -0.01 & 0.96 & 0.08 & 0.07 & -0.22 & 0.02 \\
\hline VE_7OA_Intake & -0.07 & 0.88 & -0.04 & -0.43 & -0.18 & -0.03 & -0.05 \\
\hline VE_8OA_Duct_NearBuild & 0.59 & 0.75 & -0.19 & 0.00 & -0.09 & 0.20 & 0.06 \\
\hline VE_9OADuct_Street & 0.41 & 0.30 & 0.08 & 0.79 & -0.25 & 0.24 & -0.02 \\
\hline VE_I0OADuct_Obstruct & 0.11 & 0.89 & 0.00 & 0.39 & 0.00 & 0.19 & 0.10 \\
\hline VE_IIOA_Duct_CarPk & 0.96 & 0.01 & 0.12 & 0.13 & 0.24 & -0.02 & 0.01 \\
\hline VE_I3HeavyInd_Near & 0.99 & 0.05 & -0.03 & 0.07 & 0.02 & 0.07 & -0.02 \\
\hline VE_I4Constuction_Near & 0.10 & 0.68 & 0.20 & 0.03 & 0.58 & 0.08 & 0.37 \\
\hline VE_I5OAGolnside & -0.11 & -0.03 & 0.43 & 0.35 & 0.66 & 0.46 & 0.19 \\
\hline VE_I6Schedule & 0.28 & 0.70 & 0.18 & 0.01 & 0.50 & -0.35 & -0.14 \\
\hline VE_I7CheckLeak & -0.10 & 0.89 & 0.33 & 0.26 & 0.14 & -0.07 & 0.02 \\
\hline VE_I8 AHU_housekeep & -0.17 & -0.07 & 0.91 & 0.22 & 0.22 & -0.11 & 0.18 \\
\hline
\end{tabular}


Table 3A (Continued)

\begin{tabular}{|c|c|c|c|c|c|c|c|}
\hline & DI & D2 & D3 & D4 & D5 & D6 & D7 \\
\hline IAQP_IOut_Odor & 0.30 & -0.04 & 0.38 & 0.65 & 0.33 & 0.28 & 0.39 \\
\hline IAQP_2 dayOdor & 0.82 & 0.14 & -0.26 & 0.08 & $-0.4 \mathrm{I}$ & 0.24 & -0.07 \\
\hline IAQP_3Freshness & -0.39 & 0.66 & -0.14 & -0.13 & 0.06 & 0.58 & 0.17 \\
\hline IAQP_4InOdor & 0.44 & 0.82 & -0.20 & 0.25 & 0.14 & 0.00 & -0.09 \\
\hline IAQP_5In_dayOdor & 0.29 & 0.00 & 0.05 & 0.05 & -0.88 & -0.35 & 0.13 \\
\hline IAQP_6Freshness_In & -0.66 & 0.61 & 0.18 & 0.13 & -0.06 & 0.24 & 0.29 \\
\hline IAQP_7noise & 0.06 & 0.91 & 0.01 & -0.22 & 0.19 & 0.13 & 0.25 \\
\hline IAQP_8lighting & -0.31 & 0.37 & 0.78 & 0.14 & -0.07 & 0.16 & 0.33 \\
\hline ICOP_IGeneral & -0.85 & -0.01 & 0.41 & -0.06 & 0.10 & -0.30 & -0.09 \\
\hline ICOP_2ConductIAQ & 0.04 & 0.54 & 0.40 & 0.70 & -0.15 & 0.14 & 0.04 \\
\hline ICOP_3IAQCond & -0.55 & 0.41 & 0.36 & 0.28 & -0.43 & -0.18 & 0.33 \\
\hline ICOP_4ConductlAQWhy & -0.76 & -0.25 & 0.22 & 0.08 & 0.27 & 0.20 & 0.44 \\
\hline ICOP_5Interest & 0.00 & 0.00 & 0.00 & 0.00 & 0.00 & 0.00 & 0.00 \\
\hline ICOP_6SBS & -0.24 & -0.91 & 0.04 & -0.25 & -0.01 & 0.10 & 0.20 \\
\hline Eigenvalue & 20.53 & $|7.7|$ & 9.21 & 6.43 & 5.44 & 4.62 & v3.05 \\
\hline Variability (\%) & 30.64 & 26.44 & 13.75 & 9.60 & 8.12 & 6.90 & 4.56 \\
\hline Cumulative\% & 30.64 & 57.08 & 70.82 & 80.42 & 88.54 & 95.44 & 100.00 \\
\hline
\end{tabular}

Abbreviations: G, General; HE, health effect; SR, source of contaminants; VE, ventilation; IAQP, indoor air quality perception; ICOP, industry code of practice (ICOP-IAQ).

of "fresh air." Limited understanding of the IAQ and air handling unit (AHU) as the main source of fresh and clean air can lead to them being the major source of pollutants. ${ }^{38,39}$ Odor-related complaints is a very good example of human senses indicating the existence of chemical pollutants in the indoor environment. ${ }^{40}$

VF2, explaining $26.44 \%$ of the total variance, had strong positive loading for complaints on fungal-related issues, namely, odor, fungal, temperature, overcrowding, dampness, thermostat, partition, fresh air intake, and other freshness-related complaints (Table 3B), thus representing the influence of fungi, mold growth, and temperature/humidity issues inside the building. Complaints related to dampness, sick building syndrome, temperature, and humidity are a precursor to mold growth. The basic principle of microbial agent growth consists of five important elements: mold spores (which are already in the air), nutrients (cellulose dust and starch), temperature $\left(5^{\circ} \mathrm{C}-50^{\circ} \mathrm{C}\right)$, relative humidity $(>70 \%)$, and oxygen. Humidity and temperature above or below the range of the suggested guideline indicates that the MVAC needs to be inspected. ${ }^{2,41,42}$

VF3, explaining $13.75 \%$ of the total variance, had strong positive loadings for complaints on hazardous substance, smoking, AHU housekeeping, and ergonomic factors - lighting. VF3, within the HC classification, can be credited to the lack of policy and awareness of IAQ and its effect on people. For example, in Malaysia, the smoking ban policy has not been regulated successfully in commercial establishments and, as a result, the majority of OSH complaints (as presented in this paper) related to $\mathrm{HC}$ might be due to smoking. In government buildings nowadays, strong implementation of a smoke-free environment has been established and enforced by the Ministry of Health, local authorities, and occupational health-related authorities.

VF4, explaining $9.60 \%$ of the total variance, had strong positive loadings for complaints on radiant heat, ventilation blockage, location of building, and IAQ awareness. This can be explained by taking into consideration the large number of people in Malaysia who do not really understand the IAQ concept and the majority of workers who do not care about the indoor environment they stay and work in. ${ }^{8}$ Not only is radiant heat influenced by poor building design, it reflects the poor understanding and implementation of "green" ideas among architects and engineers.

VF5, explaining $8.12 \%$ of the total variance, had strong positive loadings for complaints on vacuuming/cleaning activities in the office, ventilation diffuser status (dirt and block), and odor-related fresh air. This reflects the poor management of cleaning activities in the use of green products to clean the office environment, ducting, and diffuser. Researchers have shown that the diffuser condition (dusty) indicates poor filtration causing excess dust to be deposited on the diffuser, which can lead to sickness and absenteeism if not cleaned. ${ }^{43-46}$

VF6, explaining $6.90 \%$ of the total variance, had strong positive loadings for complaints on window heat and ventilation blockage. VF7, explaining $4.56 \%$ of the total 


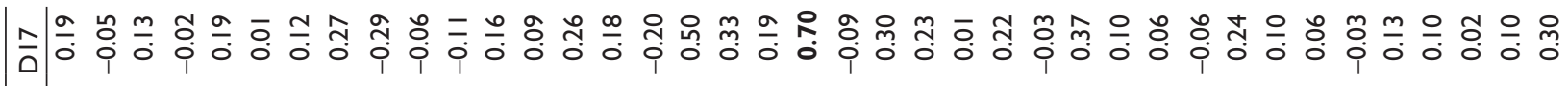

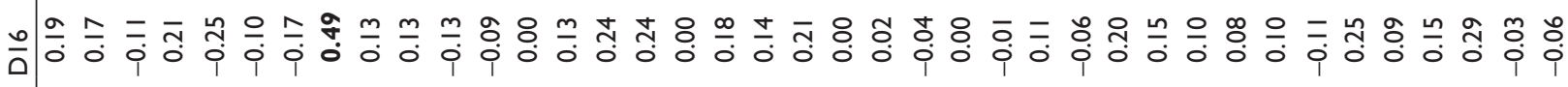

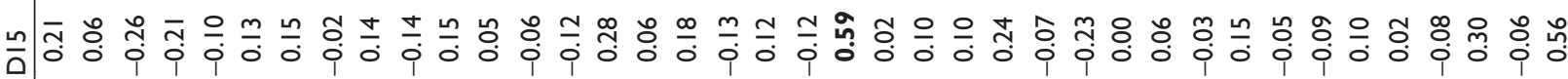

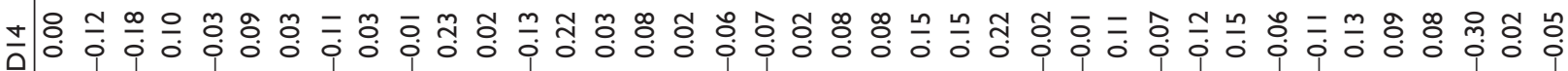

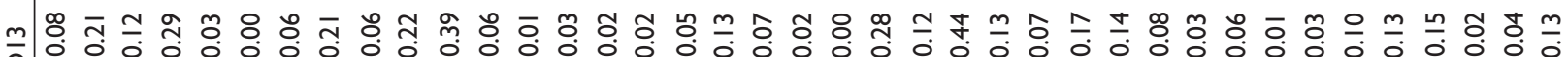

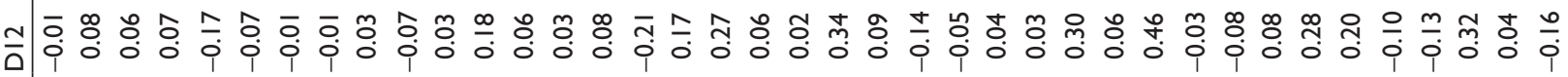

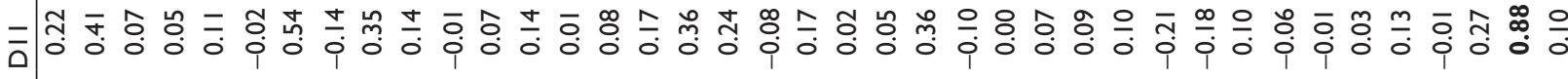

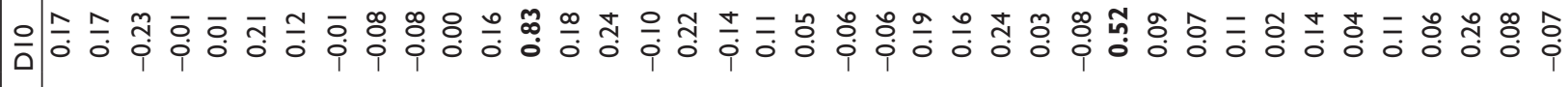
m tน ấi œ

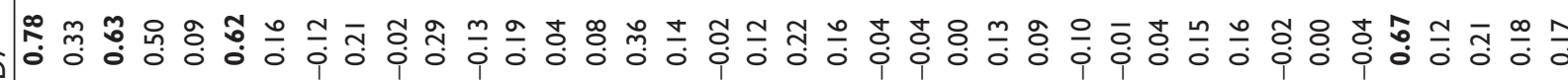

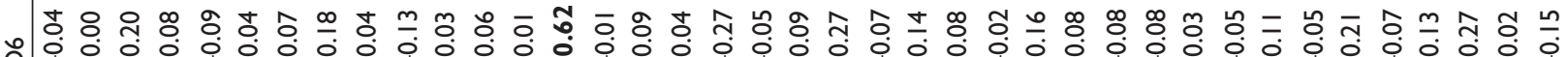

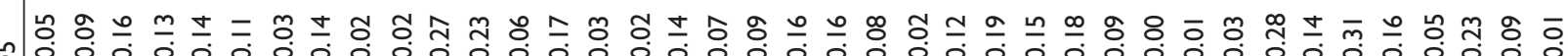
ט

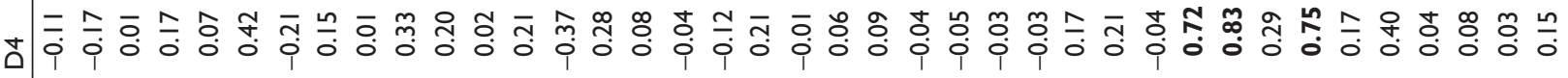

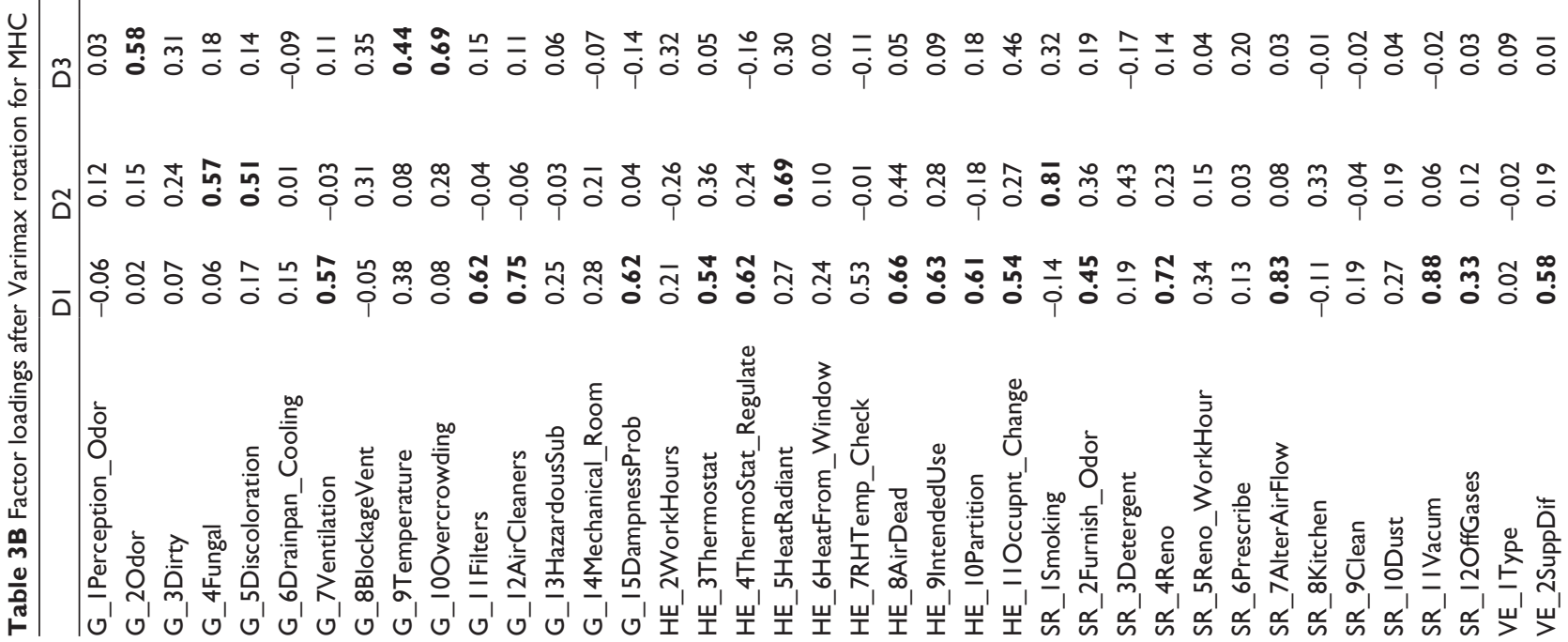




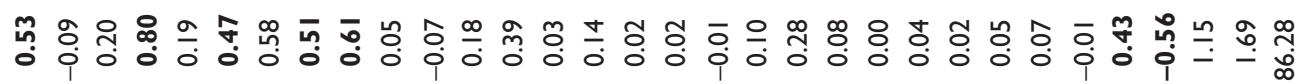

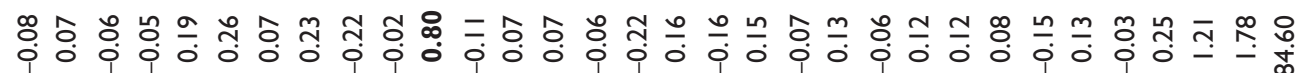

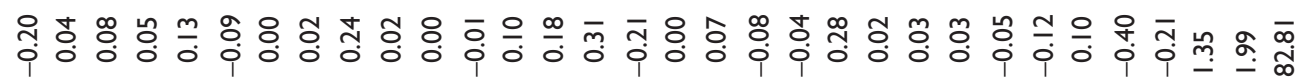

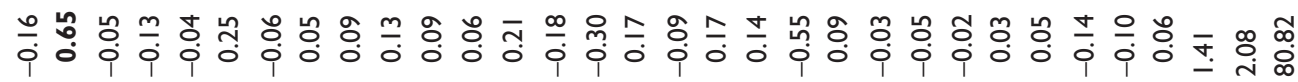

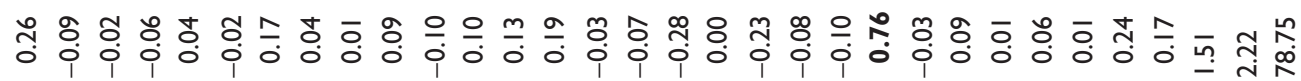

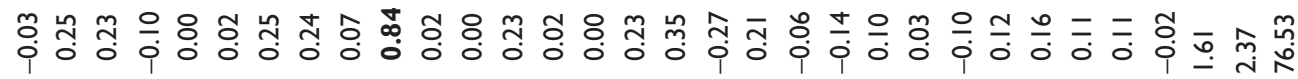

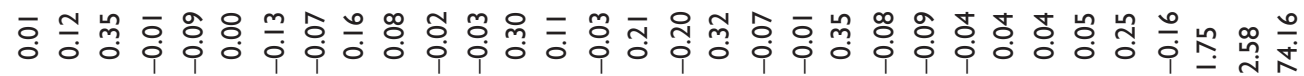

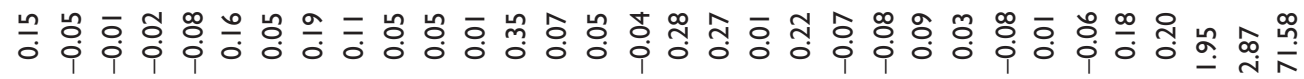

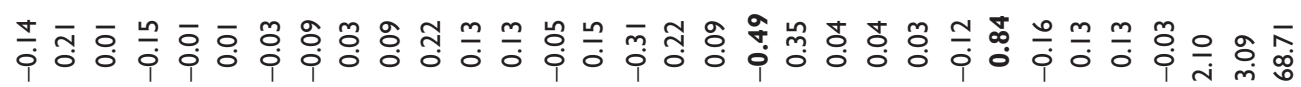

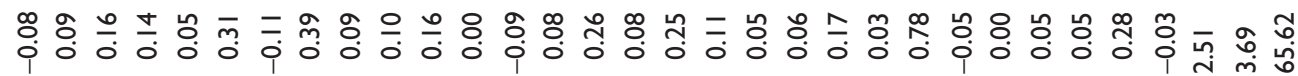

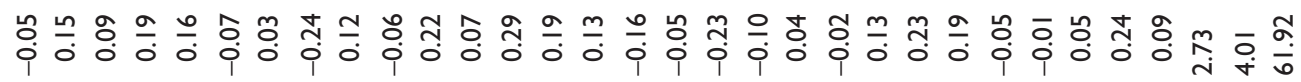

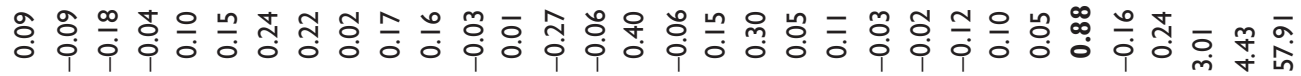

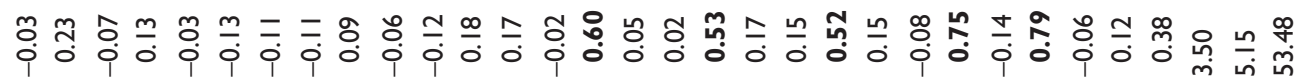

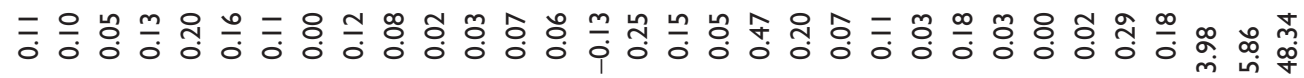

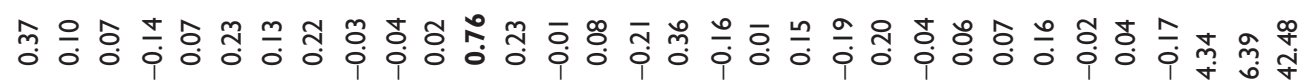

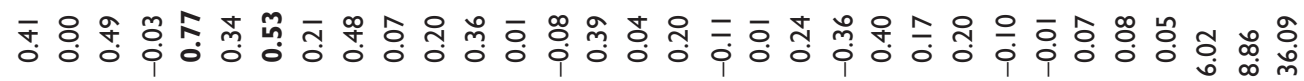

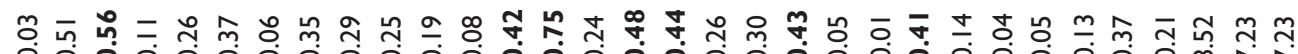

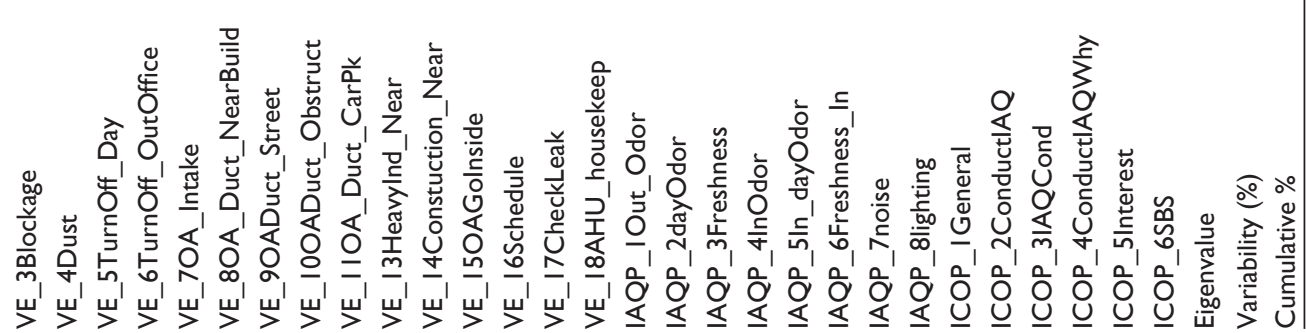




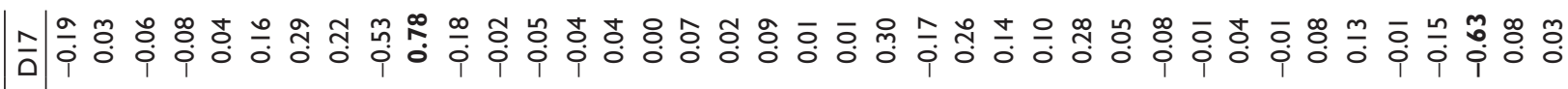

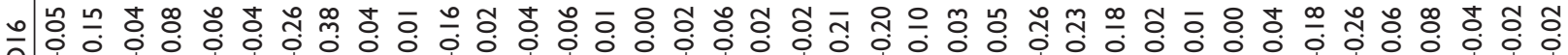

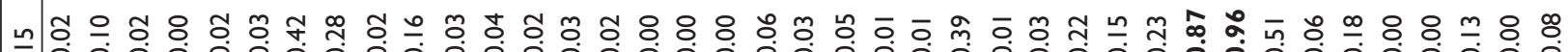

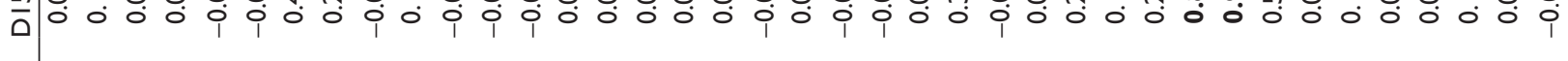

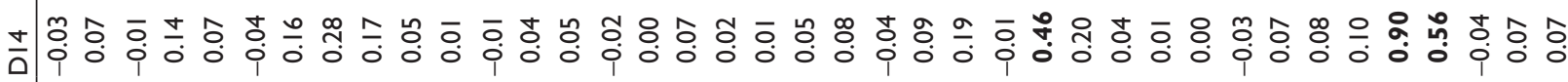
m

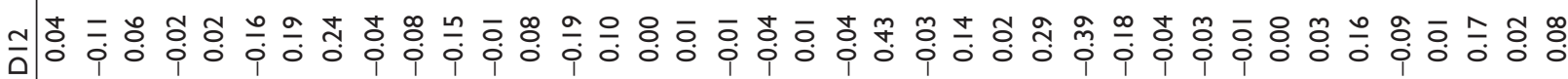

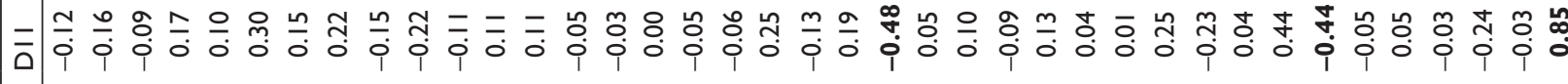

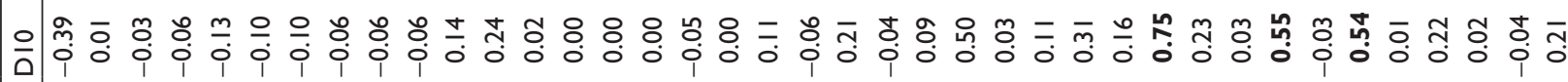

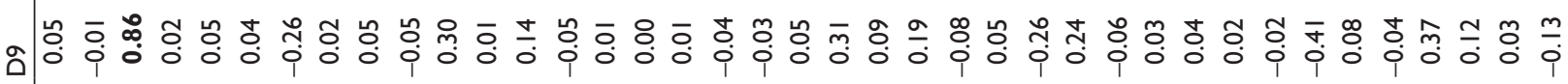

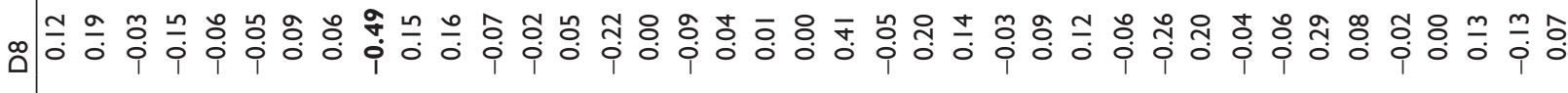
人践

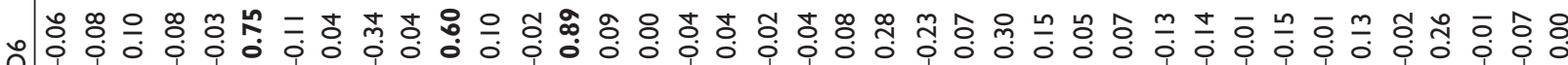

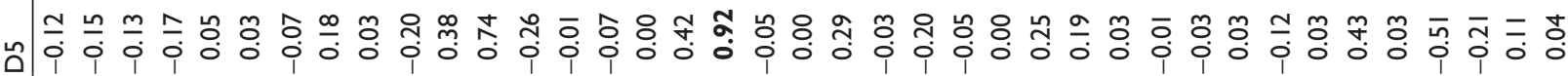

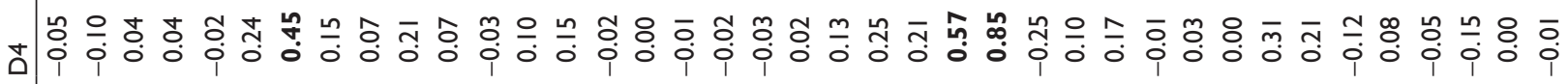

บ 文 产

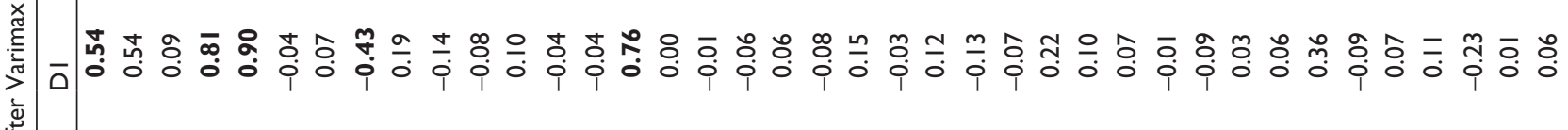

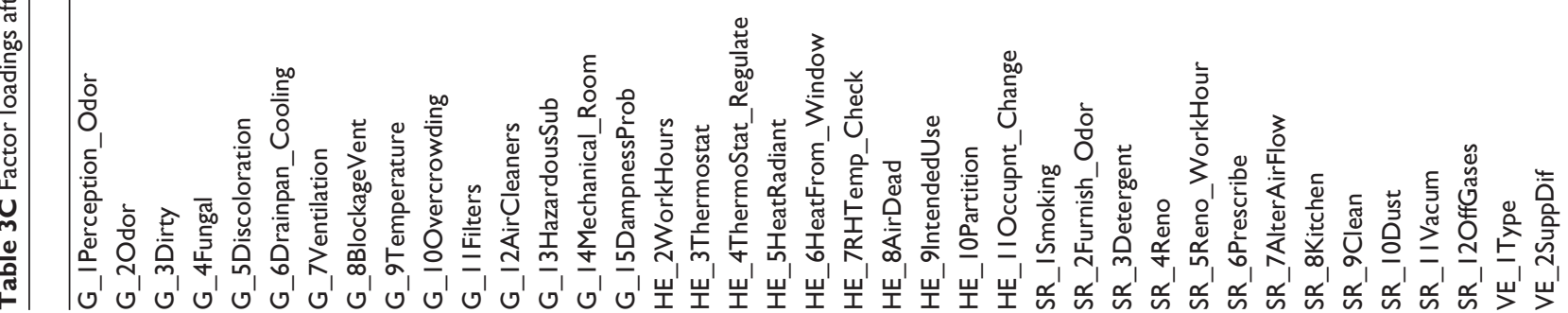




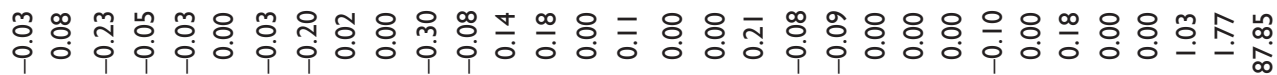

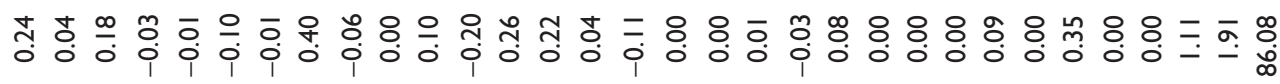

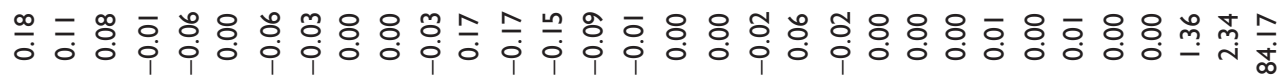

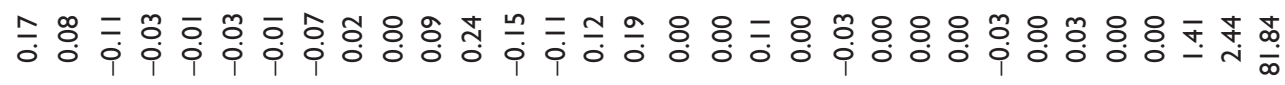

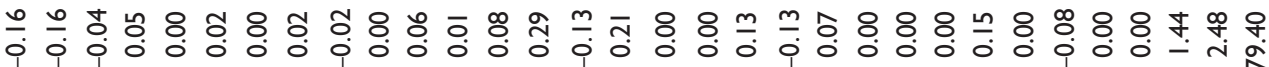

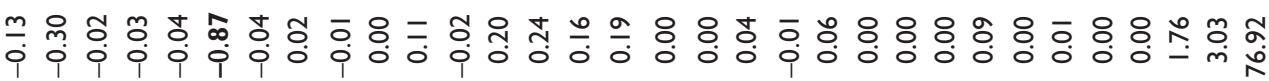

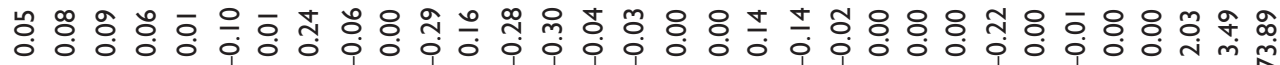

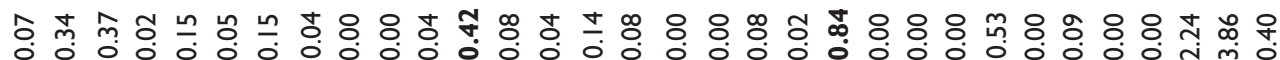

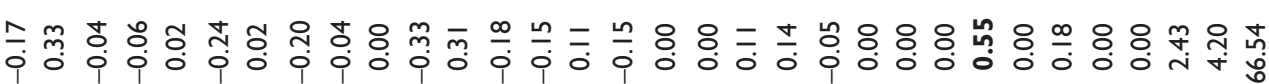

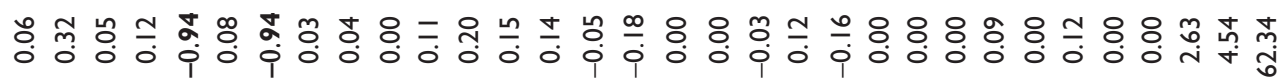

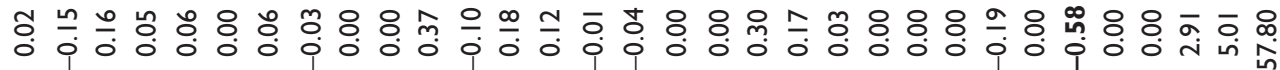

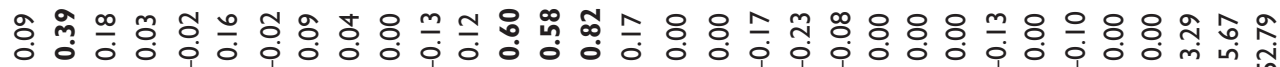

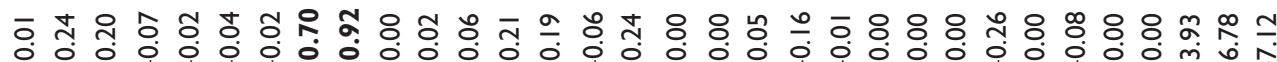

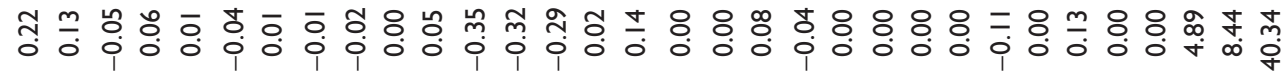

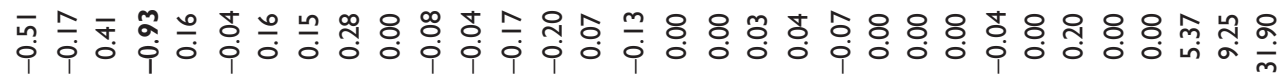

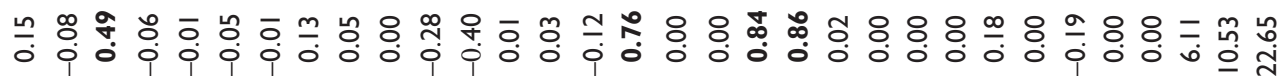

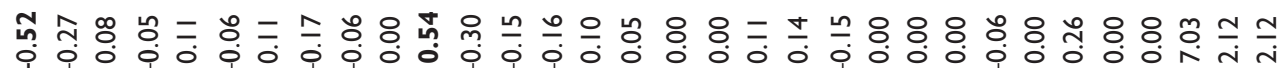

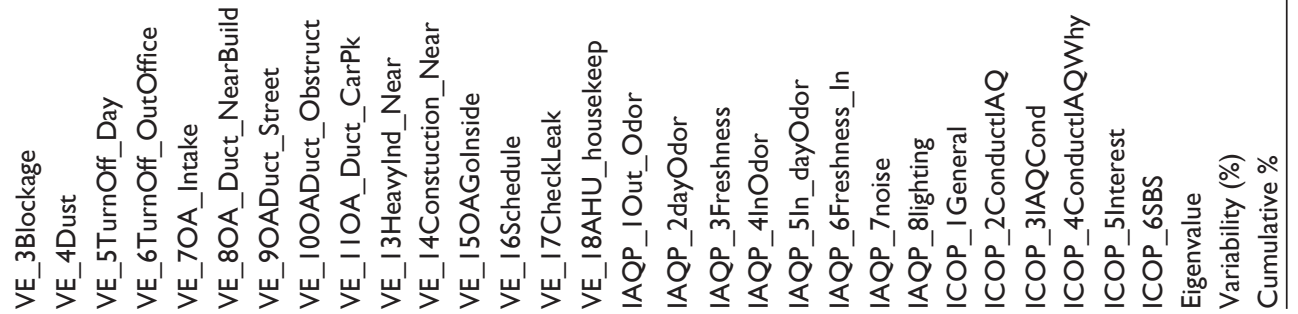


variance, had strong positive loadings for complaints on filters, air cleaners, and mechanical room. These factors are mainly due to poor response and maintenance by building owners/facilities managers, who are not making the health and safety of their occupants their main priority. This is supported by previous studies that showed poor response of facilities managers to IAQ, only responding once a problem had occurred. ${ }^{3,8,45}$ Therefore, a proactive and enhancement program is needed for owners/managers to understand the concept of IAQ and the effect of poor building management.

\section{MHC description of response from IAQ checklist}

VF1, explaining $27.75 \%$ of the total variance, had strong loadings for complaints on ventilation, filters, air cleaners, dampness, dead air, air flow, and leak, and weak/moderate positive loadings for complaints on furnishings odor, general odor sense, offgassing material, and lighting (Table 3B). These factors could be caused by chemical components from various indoor activities and poor management of diluting the pollutants through maintenance of the AHU/mechanical rooms. ${ }^{47,48} \mathrm{VF} 2$, explaining $9.10 \%$ of the total variance, showed strong positive loadings for complaints on fungal, radiant heat, smoking, fresh air intake, and highly congested street. These factors are related to fungal/microbial airborne contaminants and particles related to the IAQ. Congestion, high traffic, and poor positive pressure from inside the building can lead to the outdoor air being introduced into the indoor environment. VF2 shows moderate/weak loading on ventilation blockage, which is described as keeping the indoor air intact with no outdoor air seeping in. ${ }^{3,8,41}$ Outdoor air pollutants can seep into the indoor environment, as suggested by an epidemiologic study regarding IAQ in public transport. ${ }^{49}$

VF3, explaining $6.08 \%$ of the total variance, had strong positive loadings for complaints on odor, temperature, and outside air, and moderate positive loading for complaints on temperature. Strong positive loadings on odor, temperature, and outside air is suspected to originate from poor testing, adjusting, balancing, and commissioning of the building, which can be happen when the system is altered after changes in occupancy or management. ${ }^{50-53}$

VF4, explaining $5.80 \%$ of the total variance, had positive loadings for complaints on renovations and prescribed activities, and moderate/weak loading for complaints on odor. These complaints related to projects conducted indoors that posed a health risk and lacked good engineering management, eg, renovation within occupied buildings and renovation without exhaust fans. This can lead to strong odors and may cause discomfort for building occupants. It has been suggested that renovation increases the risk of developing irritation from prescribed activities conducted when a building is occupied by two to four times..$^{60,61}$

VF5, VF6, and VF7, explaining 5.31\%, 4.47\%, and $4.01 \%$ of the variance, respectively, had strong positive loadings for complaints on freshness of air, general IAQ, IAQ assessment conducted, mechanical room/s, reason for IAQ assessment, odor, dirty, and drain pan. All these elements strongly suggest a poor IAQ program and poor management of AHU in the buildings. Poor AHU maintenance can lead to the accumulation of dust, poor retrofitting of the filters, and no suitable treatment to stop slime growth on the cooling coils, all of which lead to the poor efficiency of air flow from the main duct. ${ }^{6}$ As a result, occupants will receive insufficient fresh and clean air from the supply diffuser. This will lead to sick building syndrome and related airborne illnesses such as dry throat, eye irritation, and discomfort.

VF8 and VF9, explaining $3.65 \%$ and $3.16 \%$ of the total variance, respectively, had strong positive loadings for complaints on discoloration, cleanliness, and IAQ assessment conducted, and weak/moderate negative loadings for complaints on working hours and duct obstruction. High loading on discoloration related to poor housekeeping. Management should ensure that the building cleaning program is in order and advise the cleaners to maintain a good indoor environment.

VF10, explaining $2.76 \%$ of the total variance, had strong positive loading for complaints on hazardous substance detergent. This issue is highly related to the use of strong detergent with a chemical composition that is hazardous to health. Building owners and safety officers should be aware of chemicals even when used for cleaning purposes, and mitigate and manage their use accordingly through chemical health risk assessment monitoring. ${ }^{55}$

VF11, VF12, VF13, and VF14, explaining 2.42\%, 2.33\%, $2.32 \%$, and $2.13 \%$ of the total variance, respectively, had strong loadings for complaints on ventilation type, industrial area nearby, noise, and odor, and weak loading for complaints on air freshness. Strong loading for complaints on ventilation, industrial, noise, and odor are suspected to originate from old or inefficient AHU/mechanical rooms. Proper testing, adjusting, balancing, and commissioning of the AHU is needed to maintain efficiency in diluting pollutants and removing outdoor pollutants. ${ }^{8,38,39,54}$

VF15, VF16, and VF17, explaining 2.04\%, 1.81\%, and $1.69 \%$ of the total variance, respectively, had strong loadings 
for complaints on temperature check, construction nearby, duct location, interest in IAQ, and sick building syndrome (Table 3B). These elements are suspected to influence the loading due to rapid development growth with poor management of IAQ in existing buildings. In a developing country, new buildings, an increasing number of cars, and rapid movement of people increase the chance of pollutants dispersing into the indoor environment, especially from nearby sources. Good monitoring practice and continuous environmental monitoring with data logging is crucial in helping building managers alert the nearby construction site/authorities to regularly inspect and check for factors that can affect other buildings' IAQ. ${ }^{56}$

\section{$M C$ description of response from IAQ checklist}

VF1, explaining $12.52 \%$ of the total variance, had strong positive loadings for complaints on fungal, discoloration, and dampness, and moderate positive and negative loadings for complaints on ventilation blockage, kitchen, construction nearby, and diffuser blockage. The presence of high loadings on fungal, discoloration, and dampness are highly correlated with high humidity and temperature in the buildings. ${ }^{55}$ Negative loadings of diffuser and ventilation blockage are highly correlated with the awareness of the occupants who adjust the diffuser of the air conditioning system to control the air flow, thus disturbing the centralized flow. Previous studies have suggested that air flow is related to the diffuser performance and better efficiency is strongly associated with testing, adjusting, balancing and commissioning. ${ }^{56,57}$

VF2, explaining $10.67 \%$ of the total variance, had strong positive loadings for complaints on IAQ odor and indoor odor. This is highly associated with fungal-related chemical dispersion, as described by previous researchers in regards to mold volatile organic compounds that can be emitted through the growth of fungal and other microbial contaminants. $7,44,58,59$

VF3, explaining $9.34 \%$ of the total variance, had strong positive loadings for complaints on thermostat and type of ventilation, and negative loading on the condition of ventilation after office hours. This is highly related to poor air conditioning and mechanical ventilation management. Thermostat and ventilation type are highly correlated, with many diffuser designs focused on being above the ceiling, which is why new floor diffusers were introduced to maximize air flow being distributed through occupied office zones. ${ }^{38,39,45}$

VF4, VF5, and VF6, explaining 8.47\%, 6.91\%, and 5.65\% of the total variance, respectively, had strong positive loadings for complaints on occupancy changes, thermostat regulation, outside air near carpark, drain pan, mechanical room, and AHU housekeeping. VF4, VF5, and VF6 looked into the condition of the AHU, which reflects the complaint components of the IAQ investigation. Drain pan, mechanical room, AHU, and thermostat were significantly associated with each other and were easily influenced by poor maintenance management. Basic parameters such as carbon dioxide and carbon monoxide can be easily monitored by facility management/building management personnel, and are usually neglected because the focus is only on the temperature and humidity of the building. This can lead to sick building syndrome, as mentioned previously by European researchers on IAQ and AHU performance. ${ }^{60,61}$

VF7, VF8, and VF9 explained 5.00\%, 4.43\%, and 4.33\% of the total variance, respectively. Positive loadings observed on VF7 relates to the use of hazardous substance detergent, which shows that the method of cleaning may jeopardize IAQ. The United States Environmental Protection Agency suggests that more than $25 \%$ of regular housekeeping detergents used are hazardous to health. ${ }^{37,62}$ Many cleaners also lack chemical training. ${ }^{63}$ Negative loading observed on the outside air intake relates to AHU design; in Asia, the main source of pollutants is sometimes not taken into consideration in the design/plan of AHU. Previous researchers have suggested that the office IAQ might be influenced by the intake of outdoor air. ${ }^{4}$ Loading of VF9 contributed to the dirty condition of the building.

VF10, VF11, VF12, and VF13, explaining 3.89\%, 3.52\%, $3.03 \%$, and $2.47 \%$ of the total variance, respectively, had strong positive loadings for complaints on renovation, odor, supply diffuser, radiant heat, and window heat, and negative strong loading for complaints on the outside air near the adjacent building. The strong loading of VF10 to VF13 relates to thermal comfort issues within the building. The optimum thermal condition of the building relates to thermostat regulation, clothing factors, and thermal radiation from the sun. ${ }^{55}$

VF14, VF15, VF16, and VF17, explaining 2.45\%, 2.30\%, $1.97 \%$, and $1.80 \%$ of the total variance, respectively, had strong positive loadings for complaints on dust, renovation, prescribed activities, and overcrowding. All these factors relate to the poor management of work that is hazardous to health. Prescribed activities that involve dust, painting, and cleaning, in particular, pose a threat to building occupants. $^{4}$

\section{The application of IAQ for building- related symptoms status classification}

The DOSH started the IAQ monitoring program in 2005. There have been recent updates to the COP, with parameters added in and upgraded to ICOP. This means that the IAQ checklist can be used in court as evidence of 
good practice conducted by an employer. IAQ assessment data were used to determine the health risk status and to classify the building based on hazard identification, risk assessment, and risk control and the interim IAQ standard for Malaysia. ${ }^{3,64}$ Some employers need a simple validated checklist to categorize their level of risk before engaging a professional IAQ assessor, despite the use of all parameters in the IAQ risk calculation. AHU quantitative element is not listed in the standard; however, a recent study reported that $20 \%$ of buildings are polluted by the AHU. ${ }^{4,8,55}$ Thermal comfort is another parameter that is not monitored in the DOSH-approved programs, but the level of thermal comfort that originated from AHU increases during overcrowding.

Results from the current study indicate that maintenance, indoor source, and AHU condition significantly influence IAQ variations. Looking at the IAQ checklist, IAQ parameters have not been considered in the equation. Taking these into consideration, a better classification strategy of the IAQ status using semiquantitative parameters should be reviewed. IAQ assessment currently conducted is less sensitive to the changes in pollutant types.

Based on this pilot study, researchers suggest that there will be at least 15 major factors that can contribute to building-related sickness and the possible issues that generally affect a building. This study suggests that the tropical climate condition has demonstrated some of the indicators of building-related illness or sickness. Therefore, future quantification of risk elements related to the indoor environment should be emphasized as the impact of the building and health are very much related.

\section{Recommendations}

In this study, it was shown that using at least 15 variables from the standard DA will give a distinctive pattern of early recognition of the building indicator problem. This technique should be used in future studies, which will correlate with the analysis of analytical airborne measurements with a large number of samples to show that early signs and indicators can be determined using 15 important items and selected pattern recognition in PCA. Analysis of the IAQ checklist will help the building owner to predetermine the degree of hazards and significance of risk before deciding to conduct comprehensive IAQ measurement.

Further analysis will be conducted (data will be published elsewhere) to represent the important 15 parameters in IAQ issues. Based on this cross-sectional study of IAQ checklist health risk evaluation, several recommendations should be heeded by building owners to prevent their building from becoming a source of sickness for workers:

1. Properly maintain the AHU according to the specifications of the manufacturer/ IAQ assessor/engineers.

2. Properly conduct planned preventive maintenance using approved chemical/bioenzymatic mechanism to treat the fins and cooling coils.

3. Regularly update the thermostat and check outside air intake, and conduct conditional appraisal for the AHU/ split unit system.

4. Based on this indoor air analysis, the best system of air conditioning will be centralized air conditioning, and proper maintenance of the AHU should be a priority. However, if budget constraints are an issue, a split unit system with dedicated fresh air intake (with good filtration and regulator to ensure the introduction of sufficient fresh air) can replace the centralized system.

5. From the engineering perspective, a holistic approach of building design should be integrated with the industrial hygienist/ IAQ professionals, especially when designing a commercial mix type of building to avoid cross-contaminants.

\section{Conclusion}

In this study, environmetric methods were used to investigate the spatial variations of an IAQ checklist ${ }^{8}$ of the selected facilities. Cluster analysis protocol successfully classified the 102 buildings into three different groups - HC, MHC, and MC. With this classification, optimal IAQ quantitative monitoring can be further decided by management which is believed to be associated with high costs. For spatial variations, DA shows encouraging results in discriminating the 102 locations/buildings, with 15 discriminant variables assigning $96.08 \%$ cases correctly using standard modes. Spatial variations from the IAQ checklist also suggest that 15 important items should be investigated for general IAQ condition. Application of PCA coupled with FA on the available data for each of the identified regions resulted in seven parameters responsible for major variations in IAQ complaints, especially in the $\mathrm{HC}$ areas, and 15 parameters in the MHC and MC areas. This technique can be used in other environmental health analyses, eg, the determination of pollutants for indoor or outdoor purposes.

\section{Acknowledgments}

The authors would like to thank to all coauthors and multidisciplinary researchers involved in this study. This study was conducted by a certified indoor air quality assessor registered under the Department of Occupational Safety and Health, 
Malaysia (registration number JKKP HIE 127/171-4[18]). The coauthors related to this project were Kamarul Faizal Tajaruddin (registration number JKKP HIE) and Rozalini Ahmad (registration number JKKP IS 127/438/02/5788). Special thanks to Mr Nitesh Malani from Enviroverks for his guidance and support towards this publication.

\section{Disclosure}

The authors report no conflicts of interest in this work.

\section{References}

1. Department of Occupational Safety and Health, Malaysia. Code of Practice on Indoor Air Quality. Putrajaya: Ministry of Human Resources; 2005.

2. Department of Occupational Safety and Health, Malaysia. Industry Code of Practice on Indoor Air Quality. Putrajaya: Ministry of Human Resources; 2010.

3. Syazwan AI, Juliana J, Norhafizalina O, Azman ZA, Kamaruzaman J. Indoor air quality and sick building syndrome in Malaysian buildings. Glob J Health Sci. 2009;1(2):126-135.

4. Ismail SH, Deros BM, Leman AM. Indoor air quality issues for nonindustrial work place. Int J Res Rev Appl Sci. 2010;5(3):235-244.

5. Sulaiman Z, Mohamed $M$. Indoor air quality and sick building syndrome study at two selected libraries in Johor Bahru, Malaysia. Environment Asia. 2011;4:67-74.

6. Menzies D, Popa J, Hanley JA, Rand T, Milton DK. Effect of ultraviolet germicidal lights installed in office ventilation systems on workers' health and well-being: double-blind multiple crossover trial. Lancet. 2003;362(9398):1785-1791.

7. Park JH, Schleiff PL, Attfield MD, Cox-Ganser JM, Kreiss K. Building-related respiratory symptoms can be predicted with semi-quantitative indices of exposure to dampness and mold. Indoor Air. 2004;14(6):425-433.

8. Syazwan AI, Rafee BM, Hafizan J, et al. Development of an indoor air quality checklist for risk assessment of indoor air pollutants by semiquantitative score in nonindustrial workplaces. Risk Manag Healthc Policy. 2012;5(1):17-23.

9. Simeonov V, Stefanov S, Tsakovski S. Environmetrical treatment of water quality survey data from Yantra River, Bulgaria. Mikrochim Acta. 2000;134(1-2):15-21.

10. Simeonov V, Stratis JA, Samara C, et al. Assessment of the surface water quality in Northern Greece. Water Res. 2003;37(17):4119-4124.

11. Brodnjak-Voncina D, Dobcnik D, Novic M, Zupan J. Chemometrics characterisation of the quality of river water. Anal Chim Acta. 2002; 462(1):87-100.

12. Kowalkowski T, Zbytniewski R, Szpejna J, Buszewski B. Application of chemometrics in river water classification. Water Res. 2006;40(4): 744-752.

13. Vandeginste BGM, Massart DL, Buydens LMC, De Jong S, Lewi PJ, Smeyers-Verbeke J. Handbook of Chemometrics and Qualimetrics: Data Handling in Science and Technology. Amsterdam: Elsevier; 1997.

14. Vega M, Pardo R, Barrado E, Deban L. Assessment of seasonal and polluting effects on the quality of river water by exploratory data analysis. Water Res. 1998;32(12):3581-3592.

15. Shrestha S, Kazama F. Assessment of surface water quality using multivariate statistical techniques: a case study of the Fuji river basin, Japan. Environ Model Softw. 2007;22(4):464-475.

16. Helena B, Pardo R, Vega M, Barrado E, Fernandez JM, Fernandez L. Temporal evolution of groundwater composition in an alluvial aquifer (Pisuerga river, Spain) by principal component analysis. Water Res. 2000;34(3):807-816.

17. Singh KP, Malik A, Sinha S. Water quality assessment and apportionment of pollution sources of Gomti River (India) using multivariate statistical techniques: a case study. Anal Chim Acta. 2005; 538(1-2):355-374.
18. Brown SD, Sum ST, Despagne F. Chemometrics: fundamental review. Anal Chem. 1996;68:21R-61R.

19. Alberto WD, Pilar DMD, Valeria AM, et al. Pattern recognition techniques for the evaluation of spatial and temporal variations in water quality. A case study: Squia River Basin (Cordoba-Argentina). Water Res. 2001;35:2881-2894.

20. Kannel PR, Lee S, Kanel SR, Khan SP. Chemometric application in classification and assessment of monitoring locations of an urban river system. Anal Chim Acta. 2007;582(2):390-399.

21. Adams MJ. The principles of multivariate data analysis. In: Ashurst PR, Dennis MJ, editors. Analytical Methods of Food Authentication. London: Blackie Academic and Professional; 1998:308-336.

22. Brown SD, Kowalski BR, Skogerboe RK. Assessment of the impact of coal mining on water quality by pattern recognition. Chemosphere. 1980;9:265-276.

23. Qadir A, Malik RN, Husain SZ. Spatio-temporal variations in water quality of Nullah Aik-tributary of the river Chenab, Pakistan. Environ Monit Assess. 2007;140(1-3):43-59.

24. Massart DL, Kaufman L. The Interpretation of Analytical Data by the Use of Cluster Analysis. New York, NY: John Wiley and Sons; 1983.

25. McKenna JE Jr. An enhanced cluster analysis program with bootstrap significance testing for ecological community analysis. Environ Model Softw. 2003;18(3):205-220.

26. Willet P. Similarity and Clustering in Chemical Information Systems. Letchworth: Research Studies Press; 1987.

27. Otto M. Multivariate methods. In: Kellner R, Mermet JM, Otto M, Widmer HM, editors. Analytical Chemistry. Wenheim: Wiley-VCH; 1998.

28. Forina M, Armanino C, Raggio V. Clustering with dendograms on interpretation variables. Anal Chim Acta. 2002;454(1):13-19.

29. Johnson RA, Wichern DW. Applied Multivariate Statistical Analysis. 3rd ed. Upper Saddle River, NJ: Prentice Hall; 1992.

30. Mendell MJ. Indices for IEQ and building-related symptoms. Indoor Air. 2003;13(4):364-368.

31. Sicard P, Lesne O, Alexandre N, Mangin A, Collomp R. Air quality trends and potential health effects: development of an aggregate risk index. Atmos Environ. 2011;45(5):1145-1153.

32. Reghunath R, Sreedhara Murthy TR, Raghavan BR. The utility of multivariate statistical techniques in hydrogeochemical studies: an example from Karnataka, India. Water Res. 2002;36(10): $2437-2442$.

33. Kim JO, Mueller CW. Introduction to Factor Analysis: What It Is and How To Do It. Newbury Park, CA: Sage University Press; 1987.

34. Liu CW, Lin KH, Kuo YM. Application of factor analysis in the assessment of groundwater quality in a blackfoot disease area in Taiwan. Sci Total Environ. 2003;313(1-3):77-89.

35. Juahir H, Zain SM, Yusoff MK, et al. Spatial water quality assessment of Langat River Basin (Malaysia) using environmetric techniques. Environ Monit Assess. 2011;173(1-4):625-641.

36. Juahir H, Zain SM, Toriman ME, Mokhtar M, Man HC. Application of artificial neural network models for predicting water quality index. Journal Kejuruteraan Awam. 2004;16(2):42-55.

37. Scitz TA. Indoor Air Quality Investigations: 1971 Through 1988. Cincinnati, OH: National Institute for Occupational Safety and Health; 1990.

38. American Society of Heating, Refrigerating, and Air Conditioning Engineers. ASHRAE Standard 62-2007: Ventilation for Acceptable Indoor Air Quality. Atlanta, GA: ASHRAE; 2007.

39. Turiel I, Hollowell CD, Miksch RR, Rudy JV, Young RA. The effects of reduced ventilation on indoor air quality in an office building. Atmos Environ. 1983;17(1):51-64.

40. Fang L, Clausen G, Fanger PO. Impact of temperature and humidity on the perception of indoor air quality. Indoor Air. 1998;8(2):80-90.

41. Department of Public Works, Malaysia. Guidelines on the Prevention of Mould Growth in Buildings. Putrajaya: Department of Public Works; 2009.

42. Department of Public Works, Malaysia. Guideline on Indoor Environmental Quality (IEQ) For Government Office Building. Putrajaya: Department of Public Works; 2012. 
43. Skyberg K, Skulberg KR, Eduard W, Skaret E, Levy F, Kjuus H. Symptoms prevalence among office employees and associations to building characteristics. Indoor Air. 2003;13(3):246-252.

44. Koren HS, Graham DE, Devlin RB. Exposure of humans to a volatile organic mixture. III. Inflammatory response. Arch Environ Health. 1992;47(1):39-44.

45. Simonson CJ, Salonvaara M, Ojanen T. The effect of structures on indoor humidity: possibility to improve comfort and perceived air quality. Indoor Air. 2002;12(4):243-251.

46. Norback D, Edling C. Environmental, occupational, and personal factors related to the prevalence of sick building syndrome in the general population. Br J Ind Med. 1991;48(7):451-462.

47. Melikov AK, Kaczmarczyk J. Air movement and perceived air quality. Build Environ. 2012;47(1):400-409.

48. Lagoudi A, Loizidou M, Santamouris M, Asimakopoulos D. Symptoms experienced, environmental factors and energy consumption in office buildings. Energy and Buildings. 1996;24(3):237-243.

49. Kavitha M, Jalaludin J, Abdah Md A, Zarida H, Shamsul BMT, Syazwan AI. Human sputum interleukin-6 by exposure to $\mathrm{PM}_{10}$ among bus drivers in Klang Valley. J Appl Sci. 2010;10(4):269-276.

50. Chao CY, Chan GY, Ho L. Feasibility study of an indoor air quality measurement protocol on 12 parameters in mechanically ventilated and air-conditioned buildings. Indoor Built Environ. 2001;10(1):3-19.

51. Nunnally JC, Bernstein IH. Psychometric Theory. 3rd ed. New York, NY: McGraw-Hill; 1994.

52. Baccarini D, Archer R. The risk ranking of projects: a methodology. Int J Project Manag. 2001;19(3):139-145.

53. Fang L, Clausen G, Fanger PO. Impact of temperature and humidity on perception of indoor air quality during immediate and longer wholebody exposures. Indoor Air. 1998;8(4):276-284.
54. Department of Occupational Safety and Health, Malaysia. Use and Standard of Exposure of Chemicals Hazardous to Health. Putrajaya: Ministry of Human Resources; 2000.

55. Universal Thermal Climate Index. COST action 730. 2003. Available from: http://www.utci.org/cost.php. Accessed July 17, 2012.

56. Persily AK. Evaluating building IAQ and ventilation with indoor carbon dioxide. ASHRAE Trans. 1997;103(Pt 2):193-204.

57. Beggs CB, Kerr KG, Noakes CJ, Hathway EA, Sleigh PA. The ventilation of multiple-bed hospital wards: review and analysis. Am J Infect Control. 2008;36(4):250-259.

58. Forsgren A, Persson K, Ursing J, Walder M, Borg I. Immunological aspects of humidifier fever. Eur J Clin Microbiol. 1984;3(5): 411-418.

59. Abbaszadeh S, Zagreus L, Lehrer D, Huizenga C. Occupant satisfaction with indoor environmental quality in green buildings. Indoor Air. 2004;14(Suppl 8):65-74.

60. Norback D, Wieslander G, Edling C. Occupational exposure to volatile organic compounds (VOCs) and other air pollutants from the indoor application of water based paints. Ann Occup Hyg. 1995;39(6):783-794.

61. Rampal KG. Current developments and future directions of occupational health in Malaysia. Med J Malaysia. 2000;55(3):295-298.

62. American Society of Heating, Refrigerating, and Air-Conditioning Engineers. ASHRAE Handbook: Fundamentals. Atlanta, GA: ASHRAE; 1993.

63. Baharuddin MR, Sahid IB, Noor MA, Sulaiman N, Othman F. Pesticide risk assessment: a study on inhalation and dermal exposure to 2,4-D and paraquat among Malaysian paddy farmers. J Environ Sci Health B. 2011;46(7):600-607.

64. Department of Occupational Health and Safety, Malaysia. Guidelines for Hazard Identification, Risk Assessment, and Risk Control. Putrajaya: Ministry of Human Resources; 2008.
Drug, Healthcare and Patient Safety

\section{Publish your work in this journal}

Drug, Healthcare and Patient Safety is an international, peer-reviewed open-access journal exploring patient safety issues in the healthcare continuum from diagnostic and screening interventions through to treatment, drug therapy and surgery. The journal is characterized by the rapid reporting of reviews, original research, clinical, epidemiological and

\section{Dovepress}

post-marketing surveillance studies, risk management, health literacy and educational programs across all areas of healthcare delivery. The manuscript management system is completely online and includes a very quick and fair peer-review system. Visit http://www.dovepress.com/ testimonials.php to read real quotes from published authors. 